\title{
THE PROBLEM OF CHEMICAL AFFINITY ${ }^{1}$
}

\author{
BY WILDER D. BANCROFT
}

\section{INTRODUCTION}

From the first volume of Faraday's "Experimental Researches in Electricity," I quote the following passages, numbering the paragraphs as in the original text.

852 . The theory of definite electrolytical or electrochemical action appears to me to touch immediately upon the absolute quantity of electricity or electric power belonging to different bodies. It is impossible, perhaps, to speak on this point without committing oneself beyond what present facts will sustain; and yet it is equally impossible, and perhaps would be impolitic; not to reason upon the subject. A1though we know nothing of what an atom is, yet we cannot resist forming some idea of a small particle, which represents it to the mind; and though we are in equal, if not greater, ignorance of electricity, so as to be unable to say whether it is a particular matter or matters, or mere motion of ordinary matter, or some third kind of power or agent yet there is an immensity of facts which justify us in believing that the atoms of matter are in some way endowed or associated with electrical powers, to which they owe their nost striking qualities, and among them their mutual chemical affinity. As soon as we perceive, through the teaching of Dalton, that chemical powers are, however varied the circumstances in which they are exerted, definite for each body, we learn to estimate the relative degree of force which resides in such bodies; and when upon that knowledge comes the fact, that the electricity, which we appear to be capable of loosening from its habitation for a while, and conveying from place to place, while it retains its chemical force, can be measured out, and being so measured is found to be as definite in its action

\footnotetext{
1 Amplified from an address before the American Chemical Society at the Toronto meeting.
} 
as any of those portions which, remaining associated with the particles of matter, give them their chemical relation, we seem to have found the link which connects the proportion of that we have evolved to the proportion of that belonging to the particles in their natural state.

855. Considering this close and twofold relation, namely, that without decomposition transmission of electricity does not occur; and, that for a given definite quantity of electricity passed, an equally definite and constant quantity of water or other matter is decomposed-considering also that the agent, which is electricity, is simply employed in overcoming electrical powers in the body subjected to its actionit seems a probable, and almost a natural consequence, that the quantity which passes is the equivalent of, and therefore equal to, that of the particles separated; $i$. e., that if the electrical power which holds the elements of a grain of water in combination, or which makes a grain of oxygen and hydrogen in the right proportions unite into water when they are made to combine, could be thrown into the condition of a current, it would exactly equal the current required for the separation of that grain of water into its elements again.

856. This view of the subject gives an almost overwhelming idea of the extraordinary quantity or degree of electric power which naturally belongs to the particles of matter; but it is not inconsistent in the slightest degree with the facts which can be brought to bear on this point. To illustrate this I must say a few words on the voltaic pile. ${ }^{1}$

877. The identity of the force constituting the voltaic current or electrolytic agent, with that which holds the elements of electrolytes together $(855)$, or in other words with chemical affinity, seemed to indicate that the electricity of

By the term voltaic pile, I mean such apparatus or arrangement of metals as up to this time have been called so, and which contain water, brine, acids, or other aqueous solutions or decomposable substances (476) between their plates. Other kinds of electric apparatus may be hereafter invented, and I hope to construct some not belonging to the class of instruments discovered by Volta. 
the pile itself was merely a mode of exertion, or exhibition, or existence of true chemical action, or rather of its cause; and I have consequently already said that I agree with those who believe that the supply of electricity is due to chemical powers (857).

916. In order to render more distinct the principles which I have been endeavoring to establish, I will restate them in their simplest form, according to my present belief. The electricity of the voltaic pile $(856$, note) is not dependent either in its origin or its continuance upon the contact of the metals with each other $(880,9 \mathrm{r} 5)$. It is entirely due to chemical action (882), and is proportionate in its intensity to the intensity of the affinities concerned in its production (908); and in its quantity to the quantity of matter which has been chemically active during its evolution (869). This definite production is again one of the strongest proofs that the electricity is of chemical origin.

917. As volta-electro-generation is a case of mere chemical action, so volta-electro-decomposition is simply a case of the preponderance of one set of chemical affinities more powerful in their nature, over another set which are less powerful: and if the instance of two opposing sets of such forces (89I) be considered, and their mutual relation and dependence borne in mind, there appears no necessity for using, in respect to such cases, any other term than chemical affinity (though that of electricity may be very convenient) or supposing any new agent to be concerned in producing the results; for we may consider that the powers at the two places of action are in direct communion and balanced against each other through the medium of the metals (89I), in a manner analogous to that in which mechanical forces are balanced against each other by the intervention of the lever (I03I).

9I8. All the facts show us that the power commonly called chemical affinity, can be communicated to a distance through the metals and certain forms of carbon; that the electric current is only another form of the forces of chemical affinity; that its power is in proportion to the chemical affin- 
ities producing it; that when it is deficient in force it may be helped by calling in chemical aid, the want in the former being made up by an equivalent of the latter; that, in other words, the forces termed chemical affinity and electricity are one and the same.

947. We seem to have the power of deciding to a certain extent in numerous cases of chemical affinity (as of zinc with the oxygen of water, etc.) which of two modes of action of the attractive power shall be exerted (996). In the one mode we can transfer the power onwards, and make it produce elsewhere its equivalent of action $(867,917)$; in the other it is not transferred, but exerted wholly at the spot. The first is the case of voltra-electric excitation, the other ordinary chemical affinity; but both are chenical actions and due to one force or principle.

959. With reference to the other set of cases, namely, those of local action (947) in which chemical affinity being exerted causes no transference of the power to a distance where no electric current is produced, it is evident that forces of the most intense kind must be active, and in some way balanced in their activity, during such combinations; these forces being directed so immediately and exclusively towards each other, that no signs of the powerful electric current they can produce become apparent, although the same final state of things is obtained as if that current had passed. It was Berzelius, I believe, who considered the heat and light evolved in cases of combustion as the consequences of this mode of exertion of the electric powers of the combining particles. But it will require a much more exact and extensive knowledge of the nature of electricity, and the manner in which it is associated with the atoms of matter, before we can understand accurately the action of this power in thus causing their union, or comprehend the nature of the great difference which it represents in the two modes of action just distinguished. We may imagine, but such imaginations must for the time be classed with the great mass of doubtful knowledge (876), which we ought rather to strive to diminish than to increase, 
for the very extensive contradictions of this knowledge by itself shows that but a small portion of it can ultimately prove true. $^{1}$

960. Of the two modes of action in which chemical affinity is exerted it is important to remark, that that which produces the electric current is as definite as that which causes ordinary chemical combinations; so that in examining the production or evolution of electricity in cases of combination or decomposition, it will be necessary, not merely to observe certain defects dependent upon a current of electricity, but also their quantity; and though it may often happen that the forces concerned in any particular case of chemical action may be partly exerted in one mode and partly in the other, it is only those which are efficient in producing the current that have any relation to voltaic action. Thus, in the combination of oxygen and hydrogen to produce water, electric powers to a most enormous amount are for the time active $(86 \mathrm{I}, 873)$; but any mode of examining the flame which they form during energetic combination, which has as yet been devised, has given but the feeblest traces. These therefore may not, cannot, be taken as evidences of the nature of the action; but are merely incidental results, incomparably small in relation to the forces concerned, and supplying no information of the way in which the particles are active on each other, or in which their forces are finally arranged.

96I. That such cases of chemical action produce no current of electricity, is perfectly consistent with what we know of the voltaic apparatus, in which it is essential that one of the combining elements shall form part of, or be in direct relation with, an electrolytic conductor $(921,923)$. That such cases produce no free electricity of tension, and that when they are converted into cases of voltaic action they produce a current in which the opposite forces are so equal as to neutralize each other, prove the equality of the forces in the

${ }^{1}$ Refer to 1738 , Series XIV. 
opposed acting particles of matter, and therefore the equality of electric power in those quantities of matter which are called electrochemical equivalents (824). Hence another proof of the definite nature of electrochemical action $(783$, etc.), and that chemical affinity and electricity are forms of the same power $(917$, etc.).

I03 I. A11 these effects of retardation, exhibited by decomposition against surfaces for which the evolved elements have more or less affinity, or are altogether deficient in attraction, show generally, though beautifully, the chemical relations and source of the current, and also the balanced state of the affinities at the places of excitation and decomposition. In this way they add to the mass of evidence in favor of the identity of the two; for they demonstrate, as it were, the antagonism of the chemical powers at the electromotive part with the chemical powers at the interposed parts; they show that the first are producing electric effects, and the second opposing them; they bring the two into direct relation; they prove that either can determine the other, thus making what appears to be cause and effect convertible, and thereby demonstrating that both chemical and electrical action are merely two exhibitions of one single agent or power $(9 \mathrm{I} 6$, etc.).

1737. That the different modes in which electrical excitement takes place will some day or other be reduced under one common law can hardly be doubted, though for the present we are bound to admit distinctions. It will be a great point gained when these distinctions are not removed, but understood.

I738. The strict relation of the electrical and chemical powers renders the chemical mode of excitement the most instructive of all, and the case of two isolated combining particles is probably the simplest that we possess. Here however the action is local, and we still want such a test of electricity as shall apply to it; to cases of current electricity, and also to those of static induction. Whenever by virtue of the previously combined condition of some of the acting 
particles (923) we are enabled, as in the voltaic pile, to expand or convert the local action into a current, then chemical action can be traced through its variations to the production of all the phenomena of tension and the static state, these being in every respect the same as if the electric forces producing them had been developed by friction.

I739. It was Berzelius, I believe, who first spoke of the aptness of certain particles to assume opposite states when in the presence of each other (959). Hypothetically we may suppose these states to increase in intensity by increased approximation, or by heat, etc., until at a certain point combination occurs, accompanied by such an arrangement of the forces of the two particles between themselves as is equivalent to a discharge, producing at the same time a particle which is throughout a conductor ( $\mathrm{r} 700$ ).

I740. This aptness to assume an excited electrical state (which is probably polar in those forming non-conducting matter) appears to be a primary fact, and to partake of the nature of induction (II62), for the particles do not seem capable of retaining their particular state independently of each other (II77) or of matter in the opposite state. What appears to be definite about the particles of matter is their assumption of a particular state, as the positive or negative, in relation to each other, and not of either one or other indifferently; and also the acquirement of force up to a certain amount.

I74I. It is easily conceivable that the same force which causes local action between two free particles shall produce current force if one of the particles is previously in combination, forming part of an electrolyte $(923$, I 738$)$. Thus a particle of zinc, and one of oxygen, when in presence of each other, exert their inductive forces (1740) and these at last rise up to a point of combination. If the oxygen be previously in union with hydrogen, it is held so combined by an analogous assertion and arrangement of the forces; and as the forces of the oxygen and hydrogen are for the time of combination mutually engaged and related, so when the 
superior relation of the forces between the oxygen and zinc come into play, the induction of the former or oxygen towards the metal cannot be brought on and increased without a corresponding deficiency in its induction towards the hydrogen with which it is in combination (for the amount of force in a particle is considered as definite), and the latter therefore has its force turned towards the oxygen of the next particle of water; thus the effect may be considered as extended to sensible distances, and thrown into the condition of static induction, which being discharged and then removed by the action of other particles produces currents.

I744. It seems highly probable, that excitement by friction may very frequently be of the same character. Wollaston endeavored to refer such excitement to chemical action $;{ }^{1}$ but if by chemical action ultimate union of the acting particles is intended, then there are plenty of cases which are opposed to such a view. Davy mentions some such, and for my own part I feel no difficulty in admitting other means of electrical excitement than chemical action, especially if by chemical action is meant a final combination of the particles.

I 745. Davy refers experimentally to the opposite states which two particles having opposite chemical relations. can assume when they are brought into the close vicinity of each other, but not allowed to combine. ${ }^{1}$ This, I think, is the first part of the action already described (1743); but in my opinion it cannot give rise to a continuous current unless combination take place, so as to allow other particles to act successively in the same manner, and not even then unless one set of the particles be present as an element of an electrolyte $(923,963) ; i$. e., mere quiescent contact alone without chemical action does not in such cases produce a current.

I.746. Still it seems very possible that such a relation may produce a high charge, and thus give rise to excitement by friction. When two bodies are rubbed together to produce electricity in the usual way, one at least must be an insulator.

1 Philosophical Transactions, 180x, p. 427.

2 Ibid., I807,1p. 34. 
During the act of rubbing, the particles of opposite kinds must be brought more or less closely together, the few which are most favorably circumstanced being in such close contact as to be short only of that which is consequent upon chemical combination. At such moments they may acquire by their mutual induction (1740) and partial discharge to each other, very exalted opposite states, and when, the moment after, they are by the progress of the rub removed from each other's vicinity, they will retain this state if both bodies be insulators, and exhibit them upon their complete separation.

1747. All the circumstances attending friction seems to me to favor such a view. The irregularities of form and pressure will cause that the particles of the two rubbing surfaces will be at variable distances, only a few at once being in that very close relation which is probably necessary for the development of the forces; further, those which are nearest at one time will be further removed at another, and others will become the nearest, and so by continuing the friction many will in succession be excited. Finally, the lateral direction of the separation in rubbing seems to me the best fitted to bring many pairs of particles, first of all into that close vicinity necessary for their assuming the opposite states by relation to each other, and then to remove them from each other's influence while they retain that state.

From Helmholtz's Faraday Lecture ${ }^{1}$ I quote the following paragraphs:

"I beg to remark that hitherto we have spoken only of phenomena. The motion of èlectricity can be observed and measured. Independently of this, the motion of the chemical constituents can also be measured. Equivalents of chemical elements and equivalent quantities of electricity are numbers which express real relations of natural objects and actions. That the equivalent relation of chemical elements depends on the pre-existence of atoms may be hypothetical, but we have not yet any theory sufficiently developed which can

${ }^{1}$ Jour. Chem. Soc., 39, 277 (1881). 
explain all the facts of chemistry as simply and as consistently as the atomic theory developed in modern chemistry.

"Now the most startling result of Faraday's law is perhaps this. If we accept the hypothesis that the elementary substances are composed of atoms, we cannot avoid concluding that electricity also, positive as well as negative, is divided into definite elementary portions, which behave like atoms of electricity. As long as it moves about on the electrolytic liquid, each ion remains united with its electric equivalent or equivalents. At the surface of the electrodes decomposition can take place if there is sufficient electromotive force, and then the ions give off their electric charges and become electrically neutral.

"The same atom can be charged in different compounds with equivalents of positive or of negative electricity. Faraday pointed out sulphur as being an element which can act either as anion or cation. It is anion in sulphide of silver, a cation perhaps in strong sulphuric acid. Afterwards he suspected that the deposition of sulphur from sulphuric acid might be a secondary result. The cation may be hydrogen, which combines with the oxygen of the acid, and drives out the sulphur. But if this is the case, hydrogen recombined with oxygen to form water must retain its positive charge, and it is the sulphur, which in our case must give off positive equivalents to the cathode. Therefore this sulphur of sulphuric acid must be charged with positive equivalents of electricity. The same may be applied to a great many other instances. Any atom or group of atoms' which can be substituted by secondary decomposition for an ion must be capable of giving off the corresponding equivalent of electricity.

"When the positively charged atoms of hydrogen or any other cation are liberated from their combination and evolved as gas, the gas becomes electrically neutral; that is, according to the language of the dualistic theory, it contains equal quantities of positive and negative electricity; either every single atom is electrically neutralized, or one atom com- 
bines with another charged negatively. This latter assumption agrees with the inference from Avogadro's law, that the molecule of free hydrogen is really composed of two atoms.

"Now arises the question: Are all these relations between electricity and chemical combination limited to that class of bodies which we know as electrolytes? In order to produce a current of sufficient strength to collect enough of the products of decomposition without producing too much heat in the electrolyte, the substance which we try to decompose ought not to offer too much resistance to the current. But this resistance may be very great, and the motion of the ions may be very slow, so slow indeed that we should need to allow it to go on for hundreds of years before we should be able to collect even traces of the products of decomposition; nevertheless all the essential attributes of the process of electrolysis could subsist. In fact we find the most various degrees of conducting power in various liquids. For a great number of them, down to distilled water and pure alcohol, we can observe the passage of the current with a sensitive galvanometer. But if we turn to oil of turpentine, benzene, and similar substances, the galvanometer becomes silent. Nevertheless these fluids also are not without a certain degree of conducting power. If you connect an electrified conductor with one of the electrodes of a cell filled with oil of turpentine, the other with the earth, you will find that the electricity of the conductor is discharged unmistakably more rapidly through the oil of turpentine than if you take it away and fill the cell only with air.

"We may in this case also observe polarization of the electrodes as a sympton of previous electrolysis. Connect the two pieces of platinum in oil of turpentine with a battery of eight Daniells, let it stay 24 hours, then take away the battery, and connect the electrodes with a quadrant electrometer; it will indicate that the two surfaces of platinum, which were homogeneous before, produce an electromotive force which deflects the needle of the electrometer. The electromotive force of this polarization has been determined 
in some instances by Mr. Picker in the laboratory of the University of Berlin; he has found that the polarization of alcohol decreases with the proportion of water which it contains, and that that of the purest alcohol, ether, and oil of turpentine, is about 0.3 , that of benzene 0.8 of a Daniell's element. ...."

"All these facts show that electrolytic conduction is not at all limited to solutions of acids or salts. It will, however, be rather a difficult problem to find out how far the electrolytic conduction is extended, and I am not yet prepared to give a positive answer. What I intended to remind you of was only that the faculty to be decomposed by electric motion is not necessarily connected with a small resistance to the current. It is easier for us to study the cases of small resistance, but the illustration which they give us about the connection of electric and chemical force is not at all limited to the acid and saline solutions usually employed.

"Hitherto we have studied the motions of ponderable matter as well as of electricity, going on in an electrolyte. Let us now study the forces which are able to produce these motions. It has already appeared somewhat startling to everybody who knows the mighty power of chemical forces, and the enormous quantity of heat and mechanical work which they are able to produce, how exceedingly small is the electric attraction at the poles of a battery of two Daniell's cells, which nevertheless is able to decompose water. One gram of water, produced by burning hydrogen with oxygen, develops so much heat, that this heat transformed by a steam engine into mechanical work would raise the same weight to a height of $1,600,000$ meters. And on the contrary we require to use the most delicate contrivances to show that a gold leaf or a little piece of aluminum hanging on a silk fiber can be at all moved by the electric attraction of the battery. The solution of this riddle is found if we look at the quantities of electricity with which the atoms appear to be charged.

"The quantity of electricity which can be conveyed by a 
very small quantity of hydrogen, when measured by its electrostatic forces, is exceedingly great. Faraday saw this, and endeavored in various ways to give at least an approximate determination. He ascertained that even the most powerful batteries of Leyden jars, discharged through a voltameter, give scarcely any visible traces of gases. At present we can give definite numbers. The electrochemical equivalent of the electromagnetic unit of the galvanic current has been determined by Bunsen, and more recently by other physicists. This determination was followed by the very difficult comparison of the electromagnetic and electrostatic effects of electricity, accomplished at first by Professor W. Weber, and afterwards under the auspices of the British Association by Professor Clerk Maxwell. The result is, that the electricity of I mg of water, separated and communicated to two balls, I $\mathrm{km}$ distant, would produce an attraction between them equal to the weight of $26,800 \mathrm{~kg}$.

"As I have already remarked, the law that the intensity of the force is inversely proportional to the quantities of attracting and of attracted mass, holds good as well in the case of gravitation as in that of electric attraction and repulsion. We may, therefore, compare the gravitation acting between two quantities of hydrogen and oxygen with the attraction of their electric charges. The result will be independent of the size and the distance of these quantities. We find that the electric force is as great as the gravitation of ponderable masses, being $7 I$, ooo billion times greater than that of the oxygen and hydrogen containing these electric charges.

"The total force exerted by the attraction of an electrified body upon another charged with opposite electricity is always proportional to the quantity of electricity contained on the attracting as on the attracted body.

"Although, therefore, the attracting forces exerted by the poles of a little battery able to decompose water on such electric charges as we can produce with our electric machines, are very moderate, the forces exerted by the same little ap- 
paratus on the enormous charges of the atoms in I $\mathrm{mg}$ of water may very well compete with the mighitiest chemical affinity.

"If we now turn to investigate how the motions of the ponderable molecules are dependent upon the action of these forces, we must distinguish two different cases. At first we may ask what forces are wanted to call forth motions of the ions with their charge through the interior of the fluid; secondly, what are wanted to separate the ion from the fluid and its previous combinations?

"I Let us begin with the case in which the conducting fluid is surrounded everywhere by insulating bodies. Then no electricity can enter, none can go out through its surface, but positive electricity can be driven to one side, negative to the other, by the attracting and repelling forces of external electrified bodies. This process going on as well in every metallic conductor is called 'electrostatic induction.' Liquid conductors behave quite like other metals under these conditions. Great quantities of electricities are collected, if large parts of the surfaces of the two bodies are very near to each other: Such an arrangement is called an electric condenser. We can arrange electric condensers in which one of the surfaces is that of a liquid, as Messrs. Ayrton and Perry have done lately. The water-dropping collector of electricity, invented by Sir W. Thomson, is a peculiar form of such a condenser, which can be charged with perfect regularity by the slightest electromotive force perceptible only to the most sensitive electrometer. Professor Wüllner has proved that even our best insulators, exposed to electric forces for a long time, are ultimately charged quite in the same way as metals would be charged in an instant. There can be no doubt that even electromotive forces less than I/ IOO Daniell produce perfect electrical equilibrium in the interior of an electrolytic liquid.

"Another somewhat modified instance of the same effect is afforded by a voltametric cell containing two electrodes of platinum, which are connected with a Daniell's cell, the elec- 
tromotive force of which is sufficient to decompose the electrolyte. Under this condition the ions carried to the electrodes cannot give off their electric charges. The whole apparatus behaves, as was first accentuated by Sir W. Thomson, like a condenser of enormous capacity. The quantity of electricity, indeed, collected in a condenser under the same electromotive force is inversely proportional to the distance of the plates. If this is diminished to $I / I O O$, the condenser takes in roo times as much electricity as before. Now, bringing the two surfaces of platinum and of the liquid into immediate contact, we reduce their interval to molecular distances. The capacity of such a condenser has been measured by Messrs. Varley, Kohlrausch and Colley. I have nxyself made some determinations which show that oxygen absorbed in the fluid is of great influence on the apparent value. By removing all traces of gas $I$ have got a value a little smaller than that of Kohlrausch, which shows that if we divide equally the total value of the polarization between two platinum plates of equal size, the distance between the two strata of positive and negative electricity, the one lying on the last molecules of the metal, the other on those of the fluid, ought to be a ten millionth part (Kohlrausch $1 / 15,000,-$ ooo) of a millimeter. We always come nearly to the same limit, when we calculate the distances through which molecular forces are able to act, as already shown in several other instances by Sir W. Thomson.

"Owing to the enormous capacity of such an electrolytic condenser, the quantity of electricity which enters into it, if it is charged even by a feeble electromotive force, is sufficiently great to be indicated easily by a galvanometer. What I now call charging the condenser, I have before called polarizing the metallic plate. Both, indeed, are the same process, because electric motion is always accompanied in the electrolytes by chemical decomposition.

"Observing the polarizing and depolarizing currents in a cell like that represented in Fig. I, we can observe these phenomena with the most feeble electromotive forces of 
I I 000 Daniell, and I found that down to this limit the quantity of electricity entering into the condenser was proportional to the electromotive force by which it was collected. By taking larger surfaces of platinum, I suppose it will be possible to reach a limit much lower than that. If any chemical force existed besides that of the electrical charges which could bind all the pairs of opposite ions together, and required any amount of work to be vanquished, an inferior limit ought to exist to such electromotive forces as are able to attract the ions to the electrodes, and to charge these as condensers. No phenomenon indicating such a limit has as yet been discovered, and we must, therefore, conclude that no other force resists the motions of the ions through the interior of the liquid than the mutual attractions of their electric charges. These are able to prevent the atoms of the same kind which repel each other from collecting at one place, and atoms of the other kind attracted by the former from collecting at any other part of the fluid, as long as no external electric force favors such distribution. The electric attraction, therefore, is able to produce an equal distribution of the opposite constituent atoms throughout the liquid, so that all parts of it are neutralized electrically as well, as chemically. ...."

"The electrical force acting on equal quantities of electricity situated at the inside of one of the electric strata of a condenser is proportional to the electromotive force which has charged the condenser, and inversely proportional to the distance of the charged surfaces. If these are $\mathrm{I} / \mathrm{roO} \mathrm{mm}$ apart, it is roo times as great as if they are I mm apart. If we come, therefore, to molecular distances, like those calculated from the measurement of the capacity of polarized electrodes, the force is ten million times as great, and becomes able, even with a moderate electromotive force; to compete with its electric charge, and hold the atoms bound to the liquid.

"Such is the mechanism by which electric force is concentrated at the surface of the electrodes and increased in its intensity to such a degree that it becomes able to overpower 
the mightiest chemical affinities we know of. If this can be done by a polarized surface, acting like a condenser charged by a very moderate electromotive force, can the attractions between the enormous electric charges of anions and cations be an unimportant and indifferent part of chemical affinity?"

"Faraday very often....... [expresses] his conviction that the forces termed chemical affinity and electricity are one and the same. I have endeavored to give you a survey of the facts connected with the question, and to avoid as far as possible the introduction of hypotheses, except the atomic theory of modern chemistry. I think the facts leave no doubt that the very mightiest among the chemical forces are of electric origin. The atoms cling to their electric charges, and opposite electric charges cling to each other; but I do not suppose that other molecular forces are excluded, working directly from atom to atom. Several of our leading chemists have lately begun to distinguish two classes of compounds, viz., molecular aggregates and typical compounds, the latter being united by atomic, affinities, the former not.

"Electrolytes belong to the latter class. If we conclude from the facts that every unit of affinity is charged with one equivalent either of positive or of negative electricity, they can form compounds, being electrically neutral only if every unit charged positively unites under the influence of a mighty electric attraction with another unit charged negatively. You see that this ought to produce compounds in which every unit of affinity of every atom is connected with one and only one other unit of another atom. This, as you will see immediately, is the modern chemical theory of quantivalence, comprising all the saturated compounds. The fact that even elementary substances, with few exceptions, have molecules composed of two atoms, makes it probable that even in these cases electric neutralization is produced by the combination of two atoms, each charged with its full electric equivalent, not by neutralization of every single unit of affinity.

"Unsaturated compounds with an even number of unconnected units of affinity offer no objection to such an 
hypothesis; they may be charged with equal equivalents of opposite electricity. Unsaturated compounds with one unconnected unit, existing only at high temperatures, may be explained as dissociated by intense molecular motion of heat in spite of their electric attractions. But there remains one single instance of a compound which, according to the law of Avogadro, must be considered as unsaturated even at the lowest temperature, namely, nitric oxide (NO), a substance offering several very uncommon peculiarities, the behavior of which will be perhaps explained by future researches."

In I9or Nernst made an address ${ }^{1}$ at the annual meeting of the German Electrochemical Society on "The Importance of Electrical Methods and Theories for Chemistry."

"The modern physical investigations on electricity, which are chiefly concerned with electrical oscillations, ought not to mislead one into the often heard opinion that electricity is to be explained as a state of oscillations. This is like supposing that one learns something final about the nature of air by studying the vibrations in acoustic experiments. It is more true to say that the investigations, referred to, have not in any way invalidated the fluid theory of electricity, $i$. e., the conception of electricity as a substance. Electrochemistry is probably destined to carry us farther along this path.

"The field of electrochemistry is that of the formation and destruction of ions, just as that of chemistry is the change from atoms to molecules and back. In consequence of the properties of water, ions are formed chiefly in that solvent and aqueous solutions are therefore the chief subject of electrochemical investigation.

"For the investigation of solutions containing ions, we make use not only of all the purely chemical methods, but also of all those which are concerned with the electrical charge on the ions. By an application of the van't Hoff-Avogadro rule Arrhenius has shown how to determine the concentration of the ions as well as of the neutral molecules; Hittorf has

' Zeit. Elektrochemie, 7, 1005 (1901). 
established the constitution of the ions and their identity with the chemical radicals; Kohlrausch has measured their rate of migration; and Ostwald, by means of these methods, has obtained an exact measure of the strength of acids.

"The speaker's methods of determining the concentration of the ions of a metal by measuring the difference of potential between the metal and the solution, have led to the quantitative determination of amounts smaller even than those which can be detected by spectrum analysis. Ostwald, and also Arrhenius, have determined the phenomenally low degree of electrolytic dissociation of water, an exceptionally important chemical constant.

"While these methods enable us to get at the nature of the ions in very different ways, electricity also gives us the means of separating chemical compounds into their components for, by electrolysis the ions are deprived of their charges and are precipitated in a neutral form. The potential difference employed overcomes the force which tends to keep the ions as such; and since one can increase the applied potential difference indefinitely, one may overcome the strongest chemical affinities. Thus Davy succeeded in isolating the alkali metals by electrolysis and Moissan prepared fluorine.

"If on the other hand a substance, such as a metal for instance, forms ions when dissolving, there must be a displacement of electricity which is the source of the voltage of the voltaic cell (theory of Nernst). Such displacements of electricity also occur during many simple chemical reactions, such as the dissolving of a metal in an acid, where the electrical charges pass from the hydrogen, which had been present as ion, to the metal which now is transformed into ions.

"One is therefore tempted to make the assumption that all chemical forces are of electrical nature. A far-reaching analogy between chemical and electrical processes certainly exists; for the chemical reaction velocity is proportional to the driving affinity and is inversely proportional to the chemical resistance, corresponding to a kind of Ohm's law. In consequence the electromotive force of a voltaic cell must be 
looked upon as a measure of the affinity of the chemical reactions taking place in the cell. This electrical method of measuring chemical affinity is not the only one we have but, whenever applicable, it is the most accurate and the most convenient.

"Of course this does not prove in any way that the chemical forces are actually of electrical nature, and people have advanced the view that such a question is an utter waste of time and that one knows enough when one determines the magnitude of the affinity. Yet an investigator ought not to be frightened by an apparently bold attempt to discover the mechanism of the processes. It is certainly justifiable for one to ask whether a machine is driven by steam, water or electricity even if one already knows that it will give so many horse-power.

"Berzelius's theory of chemical affinity looked upon all compounds as dualistic and as consisting of a positively and a negatively electrical radical. It could not hold its own during the development of organic chemistry when a monistic view, based on the theory of valence, proved more serviceable for a large class of compounds. To-day both views appear to have a justification for one recognizes substances forming positive and negative ions, $i$. e., elements and radicals which after combining are able to take up corresponding charges of electricity under suitable conditions. But while Berzelius wished to explain the strength of affinity by the amount of the charges, we know, from Faraday's results, that equivalent quantities even of elements differing most widely in affinity carry exactly equal charges of electricity. This surprising fact finds a plausible explanation if we adopt a suggestion by Helmholtz and consider electricity as a substance of atomic structure consisting of positive and negative electrons, in which case we consider the ions as chemical compounds of the elements with such electrons. We are also led to such a chemical theory of electricity by entirely different investigations on which Kaufmann reported in his address and from which it appears that the atomic weight of the negative 
electrons is about 0.0005 . The peculiarities of the two electron elements, which distinguish them from all others, are the special manifestations of force which are so different from an attraction and.which determine their individuality just as much as other properties characterize the special nature of the other elements.

"The conception of ions as saturated chemical compounds of atom and electron leads everywhere to real consequences. Thus sodium ions are just as different from the element as sodium chloride for instance. In the molecular compounds of Werner's theory, the saturated ammonia molecules are replaceable by ions and behave chemically in an analogous manner. Similar developments are to be found in the papers of Abegg and Bodländer.

"The final conclusion from this point of view, namely the existence of a compound of the positive and negative electron, cannot be tested as yet owing to the lack of a suitable 'reagent;' but this molecule may play an important part in the world of the light-ether.

"The relation between the monistic and the dualistic points of view may be formulated somewhat as follows: all elements or radicals have an affinity for positive or negative electrons with which they form ions. They also have a nonpolar attraction for each other. This last determines, for instance, the combination of two hydrogen atoms to form hydrogen molecules; also the existence of phosphorus sulphide, iodine chloride, etc.; the existence of metal compounds; and especially the existence of carbon compounds.

"When positive and negative elements combine there is also the addition of an electron molecule which splits up when ions are formed, and it appears especially remarkable that such compounds, obviously in consequence of the addition of an electron molecule, differ surprisingly more from the components than do the compounds of similar elements where there appears to be no taking up of an electron molecule. Thus the compounds of the metals are metallic, those of the metalloids are non-metallic while the combination of sodium 
and chlorine, for instance, gives rise to a salt having entirely novel properties.

"It is also possible that there are elements which react with the positive electron alone without its being necessary for any other element to take up the negative electron. In this case the negative electron will be set free and will appear in the Becquerel rays.

"Though this chemical theory of electricity is far from being a finished structure, it has its justification in that it gives a new impetus to investigation."

While this theory of Nernst rests on the work of Faraday and of Helmholtz, it opens up a new field. Nernst is interested in the chemical theory of electricity, the chief applications of which are to aqueous solutions. In fact Nernst explicitly excludes the carbon compounds in general as being the result of a non-polar attraction. Faraday and Helmholtz, on the other hand, were especially interested in the problem whether all chemical affinity might not be electrical in nature. While it may be that Nernst's limitation is a necessary one, it is not one to be accepted until we have to. Personally, I think that there is yet a great deal of work to be done along the lines laid down by Faraday and Helmholtz as well as along those laid down by Nernst.

The dualistic theory of Berzelius was weak in two points. There was apparently no way of bringing the chloracetic acids into harmony and Berzelius made the mistake of postulating that the electrical charges were proportional to the affinity. While this was the simplest assumption to make, it was not the only one that might be made and it was not necessary to a dualistic theory. Faraday's experiments showed that the assumption was wrong and also showed what assumption should have been made. The difficulty disappears if we say that the voltage necessary to remove the charge from the ion is a measure of the affinity. If one prefers, one may say that the attraction of the ion for the electrical charge is proportional to the affinity. This last is 
Helmholtz's formulation. With this modification the theory of Berzelius becomes applicable to all ion reactions.

The fundamental weakness of the theory of Berzelius lay in its inability to deal with the substitution phenomena of organic chemistry. So long as chlorine is looked upon as always a negative radical and hydrogen as always a positive radical, the replacement of one by the other without a marked change of properties is clearly absurd. If, however, we postulate that chlorine may be positive at times or hydrogen negative, the theory of Berzelius becomes formally applicable to substitutions in organic chemistry. It may well be a question whether such a modification does not make the theory so vague as to be worthless. This is a question which I do not intend to discuss at present. I do wish to call attention to the fact that this very hypothesis has been put forward as a result of recent investigations in physical chemistry.

As a consequence of measurements on the rate of oxidation of phosphorus, sulphur and aldehyde, van't Hoff was induced to postulate the existence of positively and negatively charged oxygen atoms. " "The chief result obtained by Mr. Ewan in his work in my laboratory on the rate of oxidation of phosphorus, sulphur and aldehyde, is that after the oxidation begins (and below the mysterious limiting oxygen pressure at which the reaction is checked) the rate is very closely proportional to the square root of the oxygen pressure. This relation suggests the thought that during this slow oxidation it is not the oxygen as such which is active but the exceedingly small amount of the dissociation products which are possibly present. If we are dealing with an equilibrium corresponding to the equation

$$
\mathrm{O}_{2} \rightleftarrows 2 \mathrm{O}
$$

the rate would be proportional to the square root of the oxygen pressure. This is the view advocated by Mr. Ewan. "Now the question comes up whether this is a dissociation into atoms or into ions, $i$. e., respectively positively and

${ }^{1}$ Zeit. phys. Chem., I6, 4II (I 895). 
negatively charged ions. If one adopts the latter hypothesis, one must evidently take up the question of ozone, though in a somewhat different way than heretofore. According to views often expressed, the oxygen molecule might be half used up for slow oxidation while the remaining half might react to form ozone. According to the above proportionality with the square root of the pressure, the dissociation is not a consequence of the oxidation but probably occurs from the beginning. If there are oppositely charged dissociation products, it is quite intelligible that the oxidizable substance might react more readily with one while the remainder might give the oxygen an electrical charge which might be compensated by a secondary reaction, such as ozone formation, decolorization of indigo, etc.

"There are indications of all this in the literature. The cloud formation, for instance, during the oxidation of phosphorus is due essentially to the condensation of water vapor and occurs also in air which has been in contact with phosphorus and has then been freed from ozone by means of potassium iodide. It reminds one therefore very much of the cloud formation which Helmholtz has observed in water vapor under electrical influences. Iater, it will be shown that the primary product in oxygen 'made active' by phosphorus is not ozone because it checks the luminescence of phosphorus while ozone increases it. The primary product may therefore be electrically charged oxygen."

Stieglit $z^{1}$ has assumed the existence of chlorine cations in the reaction between hypochlorous and hydrochloric acids. From experiments with non-aqueous solvents Walden ${ }^{2}$ deduces the existence of univalent and trivalent bromine and iodine cations, of trivalent and pentavalent phosphorus cations, and of the bivalent cations $S_{2}{ }^{\prime \prime}$. In a paper on valency, Abegg says: ${ }^{9}$

"A third criterion for the existence of finite ion con-

1 Jour. Am. Cheml. Soc., 23, 796 (I901).

2 Zeit. phys. Chem., 43, 385 (1903).

${ }^{3}$ Zeit anorg. Chem., 39, 339, 375 (1904). 
centrations is to be found in a rapid chemical reaction with other ions, such as those of water in hydrolysis, when most probably either the hydrogen or the hydroxyl ions react with the oppositely charged ions of the compound, thus showing their existence. Thus through the hydroxyl ions of water or of the alkalies, many chlorides are decomposed with formation of hydrochloric acid and the hydroxyl compound of the element with which the chlorine was combined, showing thereby that the element acted as a cation. By the formation of hydrogen sulphide in aqueous solution, many sulphides show the positive nature of the element combined with the sulphur as in the case of $\mathrm{B}_{2} \mathrm{~S}_{3}, \mathrm{P}_{2} \mathrm{~S}_{3}$, etc. Beside the cations $\mathrm{Be} \cdots, \mathrm{A} 1 \cdots, \mathrm{Sn} \cdots$, etc., which occur in measurable quantities, the indirect proof of the existence of the cations $\mathrm{Sn} \cdots, \mathrm{Pb} \cdots, \mathrm{B} \cdots, \mathrm{Ti} \cdots, \mathrm{Si} \cdots$, As $\cdots, \mathrm{P} \cdots, \mathrm{S}_{2} \cdots$, I $\cdots$ and many others is shown by the fornation of hydroxyl compounds. In the same way the reaction with the hydrogen ion of water or of acids shows the existence of the negative ions $\mathrm{C}_{2}^{\prime \prime}$ in the carbides, of $\mathrm{N}^{\prime \prime \prime}$ in the nitrides, of $\mathrm{P}_{2}^{\prime \prime \prime \prime}$ in the phosphides, of $\mathrm{As}^{\prime \prime \prime}$ in the arsenides, of $\mathrm{Sb}^{\prime \prime}$ in the antimonides, since hydrogen compounds are formed on decomposition. Especially noticeable is the fact that $\mathrm{Mg}_{2} \mathrm{Si}$ is decomposed even by dilute acids and $\mathrm{Mg}_{3} \mathrm{~B}_{2}$ only by concentrated strong acids with formation of silicon and boron hydrides respectively. This shows gradations in the negative electro-affinity such that the boride contains boron anions than the silicide does silicon anions because a higher concentration of hydrogen ions is necessary to cause decomposition.

"The study of the decomposition furnishes usually an entirely definite means of determining the polar rôle of the components of a compound. Thus it might be doubtful, at first sight, whether iodine or chlorine were the positive element in such a compound as iodine monochloride. The products of hydrolysis enable us to distinguish at once. There are formed hydrochloric acid and iodine oxyacids; therefore the hydroxyl ion of the water has gone to the iodine and the hydrogen ion to the chlorine. The iodine is therefore the 
positive component and the chlorine the negative component; the compound should be called iodine chloride and not chlorine iodide.

"The metal hydrides present another interesting case. Moissan concluded fron their not conducting electricity that - to use our phraseology - the hydrogen played the part of a metalloid. This reasoning is obviously not binding because we know that electrolytic conductivity is a characteristic of compounds having components with different polarity. What Moissan thought he had shown from the absence of metallic conductivity, can be deduced more directly from his observations on the decomposition of the hydrides by water. The metals take the hydroxyl ion and are therefore the positive components. The hydrogen of the hydrides combine with the hydrogen ion of the water to form hydrogen molecules and we thus become familiar with a compound $\mathrm{H} \cdot \mathrm{H}^{\prime}$ containing chemically identical atoms with opposite polarity.

"Now fundamentally every reaction is a metathetical one, with organic compounds no less than with electrolytes and we have already considered the transition cases (preceding three paragraphs). There is no doubt but that the introduction of elements or radicals of marked polarity (metals, oxygen, halogens, etc.) into organic compounds increases the reactivity of these substances extraordinarily. We may account for this by saying that atoms or atom groups form very inert compounds with hydrogen or carbon for instance when neither of the two partners differs markedly in polarity; but that they become active when they are forced into a marked polar contrast by the presence of a strongly polar substitution product. As a simple illustration of this, $\mathrm{CH}_{3} . \mathrm{H}$ does not react with $\mathrm{HCl}$ because there is not a sufficient difference of polarity between $\mathrm{CH}_{3}$ and $\mathrm{H}$. On the other hand, $\mathrm{CH}_{3} . \mathrm{OH}$ reacts with $\mathrm{HCl}$ because the negative $\mathrm{OH}$ makes the radical $\mathrm{CH}_{3}$ more positive by contrast. The products of the double decomposition are $\mathrm{CH}_{3} \mathrm{Cl}$ and $\mathrm{H}_{2} \mathrm{O}$. $\mathrm{CH}_{3}$ reacts differently when it is combined with a metal $\left(\mathrm{Zn}\left(\mathrm{CH}_{3}\right)_{2}\right.$ for instance); it then becomes the negative com- 
ponent and the reaction products are the metallic chloride and $\mathrm{CH}_{3} . \mathrm{H}$. The result of the reaction may thus be different; in connection with this the important thing is the inter-relation between the reactivity of the molecule and the difference of polarity of its parts. It is almost superfluous to add that the molecule splits the point where the polarity changes, this however depending in the case of chemical equilibrium upon the other molecules entering into the reaction and upon the arrangement of polarity in the reaction products."

The conclusions of Abegg and Stieglitz are not necessarily correct. They rest on the assumption that all reactions are ion reactions, which has certainly not yet been established. There is also an unexplained change from electrolytic to metallic conductivity in Abegg's criticism of Moissan's conclusions in regard to the hydrides. Nernst does not accept Abegg's conclusions and looks upon the formation of hydrogen gas as due to a non-polar union. The recent work of Kraus, ${ }^{1}$ however, furnishes a strong argument in favor of 'Abegg's views. In liquid ammonia as solvent, the compound $\mathrm{NaPb}_{2}$ is apparently an electrolyte with sodium as cation and $\mathrm{Pb}_{2}{ }^{\prime}$ as anion. For the present, it is immaterial which view one holds because it is impossible to apply the theory of Berzelius effectively until we know a good deal more than we do now about the conditions under which a given substance can change from being charged positively to being charged negatively or vice-versa. The really important thing about it all is that the phenomena which wrecked the theory of Berzelius are still stumbling blocks to us to-day. The theory of valence shoved the difficulties back for fifty years or more but it did not do away with them.

\section{MIEASUREMENT OF CHEMICAL AFFINITY}

Since Helmholtz delivered his Faraday lecture, there has been a great change in regard to our knowledge of chemical affinity. People have become familiar with the theorem of Gibbs $^{2}$ that the electromotive force of a completely reversible

' Jour. Am. Chem. Soc., 29, I563 (1907).

2 Thermodynamische Studien, 390 
cell is equal to the difference of the chemical potentials. The theory of the inversion cell has been worked out by van't Hoff $^{1}$ and a number of cases have been studied quantitatively. These cases may be grouped under seven heads.

\section{Precipitation of a Metal by a Metal}

The simplest case is that in which there is only one solution, as in cells of the Clark type. These cells are completely reversible if we neglect the infinitesimal solubility of the mercurous sulphate. It should be remembered that the electromotive force of the cell is a measure of the chemical affinities involved in the reactions actually taking place. In the cell

$$
\mathrm{Zn}\left|\mathrm{ZnSO}_{4}, \underline{\mathrm{Hg}_{8} \mathrm{SO}_{4}}\right| \mathrm{Hg}
$$

the reaction is ${ }^{2}$

$$
\mathrm{Zn}+\mathrm{Sol}_{1} \cdot \mathrm{ZnSO}+\mathrm{Hg}_{2} \mathrm{SO}_{4}=\mathrm{Sol}_{2} \cdot \mathrm{ZnSO}_{4}+2 \mathrm{Hg}
$$

and not

$$
\mathrm{Zn}+\mathrm{Hg}_{2} \mathrm{SO}_{4}=-\mathrm{ZnSO}_{4}+2 \mathrm{Hg} \text {. }
$$

If the solution is saturated with respect to zinc sulphate, the reaction is

$$
\begin{aligned}
\mathrm{Zn}+\mathrm{Sol}_{1} \cdot \mathrm{ZnSO}_{4}+\mathrm{Hg}_{2} \mathrm{SO}_{4}= & \mathrm{Sol}_{2} \cdot \mathrm{ZnSO}_{4}+ \\
& (\mathrm{I}+x) \mathrm{ZnSO}_{4} 7 \mathrm{H}_{2} \mathrm{Ox}+{ }_{2} \mathrm{Hg} .
\end{aligned}
$$

What the reaction is in these cases was first pointed out clearly by Cohen. ${ }^{3}$

The Daniell cell may be taken as typical of the two-solution cells. This cell is not strictly reversible because of the inter-diffusion of the two solutions which is not reversible electrolytically. The electromotive force, as measured, includes the diffusion potential for the two solutions. In many cases this may be neglected; but in accurate work a correction must be applied. After correcting for the difference of

${ }^{1} \mathrm{Cf}$. Cohen: Studien zur chemischen Dynamik, 26o.

${ }^{2} \mathrm{Sol}_{1} \cdot \mathrm{ZnSO}_{4}$ is used to denote the initial solution of zine sulphate while $\mathrm{Sol}_{2} \cdot \mathrm{ZnSO}_{4}$ is the resultant solution.

${ }^{3}$ Zeit. phys. Chem., 34, 62 (1900). 
potential between the solutions, the electromotive force is a measure of the chemical affinity for the reaction

$\mathrm{Zn}+\mathrm{Sol}_{1} \cdot \mathrm{ZnSO}_{4}+\mathrm{Sol}_{1} \cdot \mathrm{CuSO}_{4}=\mathrm{Sol}_{2} \cdot \mathrm{ZnSO}_{4}+\mathrm{Sol}_{2} \cdot \mathrm{CuSO}_{+}+\mathrm{Cu}$.

This is not the same reaction which takes place when a piece of metallic zinc is dipped into a copper sulphate solution. Quite apart from the possible formation of an alloy, the chemical reaction involves the formation of zinc sulphate in a solution of copper sulphate containing no zinc sulphate. The chemical affinity involved is that of the reaction

$$
\mathrm{Zu}+\mathrm{Sol}_{1} \cdot \mathrm{CuSO}_{4}=\mathrm{Sol}_{2}\left(\mathrm{ZuSO}_{4}, \mathrm{CuSO}_{4}\right)+\mathrm{Cu} \text {. }
$$

Going back to the Daniell cell and changing the concentrations of the zinc sulphate and the copper sulphate solutions, we change the chemical affinity and consequently the electromotive force. ${ }^{1}$ Increasing the concentration of the zinc sulphate or decreasing the concentration of the copper sulphate decreases the electromotive force of the cell. If these changes in concentration could be made sufficiently great, the electromotive force would pass through zero and its sign would then reverse, showing that copper was now the anode and zinc the cathode. The solubility of zinc sulphate determines the maximum concentration of that salt. Theoretically it should be possible to reverse the cell by diluting the copper sulphate solution indefinitely; but this is not feasible practically, because the moment the circuit is closed even for an instant enough copper will go into solution to change things back. The same result can be accomplished by adding potassium cyanide in excess to the copper sulphate solution. There is formed potassium cuprous cyanide and potassium sulphate. This experiment shows that the potential difference between a metal and a solution of a salt of that metal does not necessarily depend on the absolute amount of that salt in solution. Further experiments have shown that one of the factors on which the potential difference depends is the concentration of the metal as ion, ${ }^{2}$ using Faraday's definition that the

${ }^{1}$ Nernst: Zeit. phys. Chem., 4, 178 (1889).

${ }^{2}$ Nernst: Ibid., 4, I 48 (1889). 
substances carried to anode and cathode by the current are the anions and cations respectively.

In the cell

$$
\mathrm{Cu}\left|\mathrm{KCu}(\mathrm{CN})_{2}, \mathrm{KCN}\right| \mathrm{ZnSO}_{4} \mid \mathrm{Zn}
$$

the reaction involved is

$$
\begin{aligned}
& \mathrm{Cu}+\mathrm{Sol}_{1} \cdot \mathrm{KCu}(\mathrm{CN})_{2}, \mathrm{KCN}+\mathrm{Sol}_{1} \cdot \mathrm{ZnSO}= \\
& \qquad \mathrm{Sol}_{2} \cdot \mathrm{KCu}(\mathrm{CN})_{2}, \mathrm{KCN}, \mathrm{K}_{2} \mathrm{SO}_{4}+\mathrm{Sol}_{2} \cdot \mathrm{ZnSO}_{4}, \mathrm{~K}_{2} \mathrm{SO}_{4}+\mathrm{Zn} .
\end{aligned}
$$

The reaction in this case is one which it would be very difficult, perhaps impossible, to duplicate chemically.

One must be on one's guard against a possible error which can easily occur with nickel and copper for instance. If one takes the ordinary, solutions, containing air and measures the cell

$$
\mathrm{Ni}\left|\mathrm{NiSO}_{4}\right| \mathrm{CuSO}_{4} \mid \mathrm{Cu}
$$

one gets almost no electromotive force. This is not because the reaction

$$
\mathrm{Ni}+\mathrm{Sol}_{1} \mathrm{NiSO}_{4}+\mathrm{Sol}_{1} \mathrm{CuSO}_{4}=\mathrm{Sol}_{2} \cdot \mathrm{NiSO}_{4}+\mathrm{Sol}_{2} \cdot \mathrm{CuSO}_{4}+\mathrm{Cu}
$$

corresponds to a zero chemical affinity. It is because that .reaction does not take place under the conditions described. The nickel becomes passive and is not attacked. In a case of this sort, it is advisable to determine decomposition voltages instead of electromotive forces. It is to this peculiarity of nickel that we owe the results obtained by Carhart ${ }^{1}$ with a so-called nickel sulphate concentration cell. The work of Euler ${ }^{2}$ and of Siemens ${ }^{3}$ showed that it was not easy to determine accurately the potential difference between nickel and a nickel sulphate solution. The discrepancy between LeBlanc's ${ }^{4}$ values for the decomposition voltage of cobalt sulphate and Neumann's $s^{5}$ values for the potential difference between cobalt and cobalt sulphate is probably due to a similar cause.

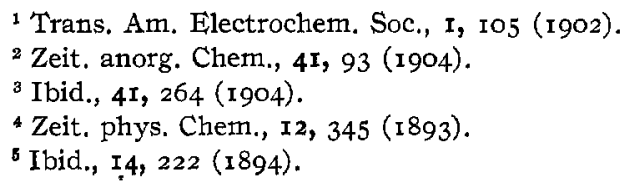




\section{Allotropic Forms of Metals}

Cohen ${ }^{1}$ has measured the difference of potential between the two forms of tin when dipped in a solution of a tin salt.

\section{Amalgam Cells}

If zinc amalgams of two concentrations are made electrode with a zinc salt as an electrolyte, the theorem of LeChatelier shows us that a current will tend to flow in such a direction as to equalize the concentrations in the two amalgams. The quantitative relations were first studied by $v$. Turin $^{2}$ and by G. Meyer. ${ }^{3}$

\section{Stable and Instable Salts.}

If we construct a cell such as

$$
\begin{array}{ll}
\text { Sat. solution } & \text { Sat. solution } \\
\mathrm{Zn}\left|\mathrm{ZnSO}_{4} 7 \mathrm{H}_{2} \mathrm{O}\right| \mathrm{ZnSO}_{4} 6 \mathrm{H}_{2} \mathrm{O} \mid \mathrm{Zn}
\end{array}
$$

or

$$
\mathrm{Hg}\left|\begin{array}{ll}
\text { Sat. solution } & \text { Sat. solution } \\
\mathrm{Hg}_{2} \mathrm{SO}_{4} \mathrm{Na}_{2} \mathrm{SO}_{4} & \mathrm{Na}_{2} \mathrm{SO}_{4} \mathrm{IOH}_{2} \mathrm{OHg}_{2} \mathrm{SO}_{4}
\end{array}\right| \mathrm{Hg}
$$

the current will flow in such a direction as to eliminate the instable salt. Only at the inversion temperature does the tendency to change and the electromotive force become zero. $^{4}$

\section{Metathetical Reactions}

We can measure the chemical affinity of such a reaction as

$$
\underline{\mathrm{TlCl}}+\mathrm{KSCN}=\underline{\mathrm{TlSCN}}+\mathrm{KCl}
$$

by arranging a cel1 ${ }^{5}$

'Tl amalgam | TlSCN, $\mathrm{KSCN}|\mathrm{KCl} \underline{\mathrm{TlCl}}| \mathrm{Tl}$ amalgam.

By changing the relative concentrations of potassium sulphocyanate and potassium chloride the current can be

${ }^{1}$ Zeit. phys. Chem., 30, 623 (1899).

2 Ibid., 5, 340 (I890); 7, 22 I (1891).

${ }^{3}$ Wied. Ann., 40, 244 (I 890); Zeit. phys. Chem., 7, 477 (I891).

4 Cohen: Zeit. phys. Chem., I4, 53 (1894); 25, 300 (1894). Cohen and Bredig: Ibid., 15, 535 (1894); 16, 453 (1895).

${ }^{6}$ Knüpffer: Ibid., 26, 255 (1898). 
made to flow in either direction. Another interesting case, illustrating the same principle, is the cell:

$$
\mathrm{Pb}\left|\mathrm{PbSO}_{4} \mathrm{~K}_{2} \mathrm{SO}_{4}\right| \mathrm{KI} \underline{\mathrm{PbI}_{2}} \mid \mathrm{Pb} \text {. }
$$

This corresponds to the reversible reaction ${ }^{1}$

$$
\underline{\mathrm{PbI}_{2}}+\mathrm{K}_{2} \mathrm{SO}_{4}=\underline{\mathrm{PbSO}_{4}}+2 \mathrm{KI}
$$

\section{Oxidation and Reduction Cells}

If we dip one platinum electrode into a solution of a reducing agent, $R$, and another electrode into a solution of an oxidizing agent, $\mathrm{O}$, we get two half cells which may be measured against each other or against a standard electrode. In the cell

$$
\mathrm{Pt}|\mathrm{R}| \mathrm{O} \mid \mathrm{Pt}
$$

the current flows through the cell from the reducing agent to the oxidizing agent. ${ }^{2}$ If the reactions are completely reversible the electromotive force is a measure of the chemical affinity. Ferrous and ferric chlorides are types of reversible reducing and oxidizing agents. On the other hand pyrogallol in alkaline solution is a powerful reducing agent but not a reversible one. We can reduce potassium chlorate to chloride, but we cannot oxidize it back again directly. The gas cells are special cases of reduction and oxidation cells but here we have very distinct difficulties; the so-called excess voltage ${ }^{3}$ giving all the effects of non-reversibility. There is one other point of interest about these cells, that the reaction in the cell is not necessarily the same that would take place if the solutions were mixed. If we take the cell

$$
\text { Pt }\left|\mathrm{Na}_{2} \mathrm{~S}\right| \mathrm{NaAc} \mid \text { AgAc } \mid \mathrm{Pt}
$$

we shall get the formation of metallic silver at the cathode, whereas we get silver sulphide if the solutions are mixed.

Klein: Zeit. phys. Chem., 36, 36I (I90I).

2 Bancroft: Ibid., Io, 387 (1892); Neumann: Ibid., 14, 226 (1894). Peters: Ibid., 26, 193 (1898).

${ }^{3}$ Caspari: Zeit. phys. Chem., 30, 89 (1899); Coehn and Osaka: Zeit. anorg. Chem., 34, 86 (1903). 


\section{Action of Light}

The effect of light on silver chloride is to cause a reduction and a partial evolution of chlorine. The amount of this decomposition and the change in chemical affinity, caused by the light, can easily be measured electrically, ${ }^{1}$ so that here also we get quantitative data.

In addition to the electrical methods of measuring chemical affinity, we have also non-electrical methods. Suppose we have equilibrium for a dissociating gas with known partial pressures, or for a dissociating solute with the partial osmotic pressures known. Knowing these data and the equilibrium formula we can calculate the work that would be done if we could displace the equilibrium mechanically. A measure of the work done in displacing an equilibrium reversibly is a measure of the chemical affinity and of the electromotive force that would be generated if the reaction could be made to take place in a voltaic cell, Since the work done in displacing the equilibrium depends on the equilibrium (or dissociation) constant, it follows that there must be a relation between the equilibrium constant and the electromotive force. This relation was formulated by van't $\mathrm{Hoff}^{2}$ in 1886 . If we write the equation for equilibrium in this form

$$
\log \mathrm{K}=\Sigma n \log c
$$

the van't Hoff relation between free energy, $F$, electromotive force, $\mathrm{E}$, and the equilibrium constant takes the form

$$
\mathrm{F}=96600 \mathrm{E}=\mathrm{RT}(\log \mathrm{K}-\Sigma n \log c)
$$

where $c$ is used to denote concentrations which may differ from the equilibrium concentrations $C$. If we arbitrarily make the concentrations of all the reacting substances equal to unity, the term $\Sigma n \log c$ disappears and our formula becomes

$$
\mathrm{F}=96600 \mathrm{E}=\mathrm{RT} \log \mathrm{K} .
$$

${ }^{1}$ I.uggin: Zeit. phys. Chem., 23, 577 (I899); Luther: Ibid,, 30, 628 (I899); Wildermann: Ibid., 4I, 87; 42, 257 (1902); 52, 209 (1905); Phil. 'Trans., 199A, 337 (I902); 206A, 335 (1906).

${ }^{2}$ Cf. Bredig: Zeit. Elektrochemie, 4, 544 (I898). 
This is a very popular way of writing the formula; but my experience is that it is rather confusing and that there is no advantage to be gained by this particular transformation. This formula has been tested experimentally for the precipitation of a metal by a metal; for amalgam cells; for stable and instable salts; for metathetical reactions; and for oxidation and reduction cells. The result of the test has been so satisfactory that we have no hesitation in calculating chemical affinity from the equilibrium phenomena in cases where it is difficult or impossible to make the reaction take place in a voltaic cell. In that most useful reaction to physical chemists, the action of alcohol on acetic acid, we should be quite put to it to arrange that as a voltaic cell. It is a reaction for which the equilibrium can be measured and formulated. The van't Hoff formula gives us a method of calculating the chemical affinity for this reaction. In most cases we make use of the electrical method if possible, because it is usually simpler and more accurate. However, if there is any reason for doubting the accuracy of the electrical methods, we fall back at once on the method of the equilibrium constant. One instance of this is to be found in the hydrogen-oxygen gas cell. No one has ever observed experimentally an electromotive force of about 1.22 volts for the gas cell; but this is the value obtained from the chemical reactions which have been studied ${ }^{1}$ and it is generally accepted as more accurate than the values obtained by direct measurement.

Since the strength of an acid is proportional to the concentration of ion, and since the concentration of hydrogen as ion at any dilution depends on the equilibrium (or dissociation) constant, it is customary to speak of this latter as the affinity constant of the acid. There is a certain confusion of ideas about this because, in the sense that we have been using the word, the equilibrium constant is a function of the chemical affinity only for the reaction $\mathrm{HX} \rightleftarrows \mathrm{H}^{*}+\mathrm{X}^{\prime}$. It is in this sense that the word is used by van't Hoff. ${ }^{2}$

${ }^{1}$ Nernst: Zeit. Elektrochemie, II, 835 (1905); Lewis: Jour. Am. Chem. Soc., 28, 17o (1906).

${ }^{2}$ Zeit. phys. Chem., 3, 608 (1889). 
While we can determine the chemical affinity whenever we have a reversible reaction which we can measure electrically or chemically, we are completely at a loss for the present with regard to reactions which are practically irreversible. $^{1}$ The inversion of cane sugar to dextrose and laevulose is a reaction running practically, if not theoretically, to an end. No one has ever succeeded in reversing it and we do not know where the equilibrium point is or even whether there is an equilibrium point. Consequently we cannot calculate the chemical affinity corresponding to this reaction. The reaction cannot be arranged as a voltaic cell. The oxidation of an alkaline pyrogallol solution is a reaction which can be studied electrometrically; but it is not reversible and therefore we cannot calculate the chemical affinity, though we may be able to assign a limiting value. To this extent we are better off than in the case of the sugar inversion where we have only a reaction velocity formula from which no conclusion can be drawn. If we are to get numerical values for the chemical affinity corresponding to apparently irreversible reactions, it seems that we should begin by making a careful study of irreversible oxidation and reduction cells. As long ago as I 892 , I called attention to the fact ${ }^{2}$ that there were two classes of reducing agents, those which formed an oxidizing agent when oxidized and those which did not. A similar distinction holds good in regard to the reduction of oxidizing agents. It would have been better to have distinguished oxidizing or reducing agents with which the reaction is readily reversible from those with which the reaction is practically irreversible; but the instances cited at the time made the meaning clear. Since then, most of the work has been on reversible oxidizing and reducing agents because the theory is simpler, but it seems to me that the time has come to take up the study of the irreversible class.

In paragraph 918 Faraday says "that the electric current is only another form of the force of chemical affinity," and

${ }^{1}$ Cf., however, v. Wartenberg: Zeit. phys. Chem, 6x, 366 (1907).

${ }^{2}$ Zeit. phys. Chem., ro, 407 (1892). 
that "the forces termed chemical affinity and electricity are one and the same." Strictly speaking, the fact that chemical energy can be converted into electrical energy is not a proof that the two are the same thing. It is only by seeing how far such a hypothesis is a successful working one that we can tell what its limitations are or whether it has limitations.

\section{Inter-pelation of Chemical and Electrolytic Action.}

The most striking characteristic of an electrolytic reaction is that it occurs in two places-at the anode and at the cathode. ${ }^{1}$ This peculiarity can be made less marked by bringing the electrodes nearer and nearer together. When the distance between them vanishes, we have a chemical reaction in the ordinary sense of the word and not an electrochemical reaction. Any chemical reaction, therefore, which can be made to take place electrolytically must consist of an anode and a cathode process. ${ }^{2}$ Considering the matter in this light we see that in the chemical reaction there is a possibility of the anode and the cathode processes interfering and perhaps of one masking the other.

In some cases it is easy enough to tell what the anode and the cathode processes are. If we dissolve zinc in sulphuric acid, the formation of zinc sulphate is the anode process and the evolution of hydrogen is the cathode process. Now we know that pure zinc does not dissolve readily in sulphuric acid. Consequently we should expect to find a difficulty of some sort if we electrolyze sulphuric acid between zinc electrodes. We find this in the form of the so-called "excess voltage" at the cathode; and in the electrolytic process we can obtain a more or less quantitative measurement of the phenomenon though we are still far from knowing the cause of it.

If we dissolve copper in sulphuric acid, the formation of copper sulphate is the anode reaction and the reduction of

${ }^{1}$ Cf. Trans. Am. Electrochem. Soc., 9, I3 (1905).

${ }^{2}$ Traube: Ber, chem, Ges, Berlin, 26, I473 (1893); Haber: Zeit. phys. Chem., 34, 513; 35, 8I, 608 (rgoo); Zeit. Elektrochemie, 7, 41 I (rgor). 
sulphuric acid is the cathode process. This same reaction. takes place electrolytically even with a more dilute acid. In the directions for the electrolytic determination of copper ${ }^{1}$ we read that "if the current be permitted to act too long in the presence of sulphuric acid, copper sulphide may be produced."

This identity of chemical reaction and electrolytic reaction has not always been admitted. Tafel ${ }^{2}$ disputes it flatly, basing his conclusion on what seems, at first sight, to be conclusive evidence. The experiments were all made with a solution containing both nitric acid and sulphuric acid.

"Nitric acid in a sulphuric acid solution is reduced electrolytically almost exclusively to hydroxylamine when an amalgamated cathode is used which has a distinct electrolytical reducing action on hydroxylamine sulphate.

"On the other hand nitric acid is converted almost completely into ammonia in presence of a copper cathode which acts more slowly and with a lower current efficiency, in spite of the fact that the copper cathode is entirely unsuited for the further reduction of hydroxylamine sulphate when once formed.

"From these facts one is justified in drawing the conclusion that hydroxylamine is not an intermediate stage in the reduction of nitric acid to ammonia at a copper cathode.

"To account for this phenomenon one may make different hypotheses and, at first sight, it may seem the simplest assumption that the formation of hydroxylamine is a specific chemical action of the metals concerned. This is certainly not correct for mercury. It has long been known that in the presence of very concentrated sulphuric acid mercury reduces nitric acid readily to nitric oxide, and mercury is used in Lunge's nitrometer for the quantitative determination of nitric acid. That a more dilute acid acts in the same way and that not a trace of hydroxylamine is formed by the action of mercury on nitric acid has been proved by me in special experiments so

1 E. F. Smith: "Electro-Analysis," 4th Ed,, 66.

${ }^{2}$ Zeit. anorg. Chemie, 31, 29I (I902). 
contrived as to duplicate the conditions of electrolysis as closely as possible.

"On the other hand, the following hypothesis seems to me to account for all the facts and to have the further advantage of bringing these facts into line with Chilesotti's ${ }^{1}$ views and experiments with regard to the effect of different cathodes on the reduction of nitrobenzene. Chilesotti concludes that, in the reduction of nitrobenzene to aniline in acid solution, ${ }^{2}$ the specific electrolytic reduction leads only to the formation of phenylhydroxylamine and that the further reduction of this substance to aniline depends chiefly on the purely chemical action of the cathode or of the metals specially added to the cathode solution.

"The matter of the electrolytic reduction of nitric acid seems to me a little different, though analogous to a certain extent. From the facts already referred to, it is impossible to avoid drawing the conclusion that the electrolytic reduction of nitric acid in sulphuric acid solution proceeds with great energy [?] as far as the formation of hydroxylamine and that this solution is not easily reduced farther.

"Special experiments have proved conclusively that the change in the course of the reaction which takes place in the presence of certain metals, notably copper, and which leads straight to ammonia, is not due to a secondary chemical action of these metals on hydroxylamine previously formed. Hydroxylamine sulphate is quite stable in presence of copper, copper sponge or copper sulphate in acid solution. I assume therefore that certain cathode materials, such as copper, change the course of the reduction from the specific electrolytic path leading from nitric acid to hydroxylamine in such a way that the reaction does not proceed through the hydroxylamine stage at all, but passes it by and forms ammonia direct. I cannot yet say certainly at what stage of the

Zeit. Elektrochemie, 7, 768 (IgOr).

${ }^{2}$ Cf. the patents of the firm, C. F. Boehringer and Sons. D. R. P., II6942, II7007 (I899); also Elbs and Silbermann: Zeit. Elektrochemie, 7, 589 (I9OI). 
reaction this change takes place but it seems to me not improbable that it occurs at that of dihydroxylamine, $\mathrm{NH}(\mathrm{OH})_{2}$. The dihydroxylamine must be looked upon as corresponding to phenylhydroxylamine in the change from nitrobenzene to aniline.

$$
\begin{array}{ccc}
\mathrm{C}_{6} \mathrm{H}_{5} \cdot \mathrm{NO}_{2} & \mathrm{C}_{6} \mathrm{H}_{5} \cdot \mathrm{NHOH} & \mathrm{C}_{8} \mathrm{H}_{5} \cdot \mathrm{NH}_{2} \\
\text { OH. } \mathrm{NO}_{2} & \text { OH.NHOH } & \text { OH.NH }
\end{array}
$$

The product corresponding to aniline is not ammonia but hydroxylamine.

"By using a mercury cathode and graded cathode potentials I shall try to furnish an experimental proof for the correctness of this hypothesis.

"Through the investigation of the electrolysis of nitric acid in sulphuric acid solution conclusive proof has been furnished that the electrolytic reduction at a special cathode (copper, mercury) may differ not only quantitatively, but qualitatively from the chemical reducing action of the cathode metal in presence of an identical electrolyte. This seems to me a result of general importance.

"In addition we have the observation that two metals, copper and mercury, which give the same product, nitric oxide, by chemical action on a mixture of nitric and sulphuric acids, produce an entirely different result when used as cathodes, the first forming ammonia almost entirely and the second almost entirely hydroxylamine.

"One's right to speak of a specific electrolytic reducing action at a definite cathode in a definite solution cannot be disputed any more, even though this specific electrolytic action is often masked by other influences.

"I have advanced the hypothesis that the formation of hydroxylamine, in other words the reducing action at a mercury cathode, is to be looked upon as a specific electrolytic reduction of nitric acid in sulphuric acid solution and that this is interfered with by chemical action in the case of other cathodes, especially copper. Therefore the combination of electrolytic reduction and chemical disturbance leads directly to ammonia while electrolytic reduction alone leads first to 
hydroxylamine and afterwards only gradually to ammonia through 'over-reduction' at cathodes with especially high hydrogen polarization.

"At many cathodes, such as tin in hydrochloric acid solution, there may also be a direct chemical reduction of nitric acid to ammonia and hydroxylamine so that here the work of the current consists entirely or partly in reprecipitating the tin that has gone into solution. But it seems to me to have been established incontrovertibly by the preceding experiments that such a point of view ${ }^{1}$ is not tenable for every electrolytic reduction at any cathode."

Further on in the same paper Tafel $^{2}$ describes experiments on the chemical action of copper, mercury, and lead on nitric acid in presence of sulphuric acid.

"The following experiments were carried out with the intention of learning whether perhaps the very different results of the electrolytic reduction of nitric acid with different cathodes might be referred to the chemical action of nitric acid on the metals in question. The experiments were therefore carried out as far as possible under the same conditions under which a possible chemical action of the metals on nitric acid must take place during [electrolytic] reduction. The experiments were therefore made in presence of a large amount of sulphuric acid, at ordinary temperature, with continuous shaking. Only in this way, at least with lead and mercury, could the conditions prevailing during electrolysis be maintained; for without vigorous shaking salts soon precipitate on the surface of the metal and prevent the further action of the nitric acid. If one assumes a possible chemical action of the metals during the electrolysis one may also make the assumption that the surface is kept in a state for the chemical reaction through continuous reprecipitation of the metal by the current.

1 For reasons which will be explained later, the fact that a reduction takes place more energetically at a definite cathode during electrolysis than with finely-divided metal without electrolysis, cannot be looked upon as a legitimate argument against such a conception.

${ }^{2}$ Zeit. anorg. Chem., 31, 309 (1902). 
"This consideration vitiates all proofs as to the existence of a specific electrolytic reduction differing from the chemical action of an attackable cathode, so long as these proofs are based only on the fact that the reduction in question takes place more energetically during electrolysis than without it; for in so far as we are dealing with readily soluble salts, we must assume that the removal of these salts from the surface of the electrode by the current will have a very beneficial effect upon the reaction.

\section{Copper, Nitric Acld and Sulphuric Acids}

"I placed ro.I grams of a thin clean piece of copper wire, cut in short pieces, in a round-bottomed flask holding about I $50 \mathrm{cc}$ and added $20 \mathrm{cc}$ of a 50 percent sulphuric acid and $2 \mathrm{cc}$ of a dilute nitric acid containing I gram $\mathrm{HNO}_{3}$. After a few seconds there began a violent evolution of gas which however soon slacked up. The flask was then placed on a horizontally-acting shaking machine and connected by means of rubber stopper and rubber tubing with a Volhard apparatus containing a concentrated solution of iron vitriol. After a brief period of shaking the evolution of gas ceased and the solution appeared cloudy. On adding $20 \mathrm{cc}$ of water and shaking some more, the evolution of gas increased and the iron vitriol solution became dark colored, owing to the absorption of large amounts of nitric oxide. After shaking for several hours the solution in the flask was turbid, due to the presence of crystallized copper sulphate, and the evolution of gas had ceased. A further addition of $20 \mathrm{cc}$ water caused the evolution of gas to begin again. The undissolved copper weighed 8.54 grams and consequently 1.65 grams $\mathrm{Cu}$ had dissolved. The equation

$$
{ }_{2} \mathrm{HNO}_{3}+3 \mathrm{Cu}+{ }_{3} \mathrm{H}_{2} \mathrm{SO}_{4}={ }_{3} \mathrm{CuSO}_{4}+{ }_{2} \mathrm{NO}+\mathrm{H}_{2} \mathrm{O}
$$

requires $\mathrm{I}_{52} 2$ grams copper for I gram $\mathrm{HNO}_{3}$.

"The slight difference between experiment and theory is due in part to the fact that in this experiment air was not rigorously excluded from the flask. Every time the flask was opened some air passed in and colored the vapor phase brown 
with formation of nitrogen dioxide. On further shaking this was reduced with a corresponding consumption of copper.

"A portion of the solution containing copper sulphate was tested for hydroxylamine by adding Seignette salt and an excess of alkali. No hydroxylamine was formed.

"The remainder of the solution was treated with an excess of concentrated caustic potash and three-quarters of it distilled into a cooled Volhard apparatus containing water. After adding a few drops of methyl orange the distilled liquid required $0.14 \mathrm{cc}$ tenth-normal hydrochloric acid to produce a red color. Just as much standard acid was needed when the same amount of a caustic potash solution was distilled by itself and the distillate titrated.

"By the action of copper on nitric acid in presence of sulphuric acid, neither ammonia nor hydroxylamine is formed in perceptible amounts.

\section{Mercury, Nitric Acid and Sulphuric Acid}

"If pure mercury is shaken with a solution of nitric acid in 50 cc sulphuric acid, it changes very quickly into a mass of little globules while brown fumes are given off and a white precipitate of mercurous sulphate is formed. There was shaken together 40 grams mercury, $20 \mathrm{cc} 50$ percent sulphuric acid and $2 \mathrm{cc}$ dilute nitric acid containing I gram $\mathrm{HNO}_{3}$ in a closed flask in a shaking machine. The flask was opened occasionally and at first a heavy pressure was noticed. After shaking for three hours the reaction was at an end. The filtrate from the mercury and the mercurous sulphate contained small amounts of nitrous acid ${ }^{1}$ which were driven out by a short boiling. After that, a portion decolorized a small amount of potassium permanganate (for the whole amount of liquid $0.6 \mathrm{cc}$ of a solution of which I cc corresponded to $1.6 \mathrm{mg}$ hydroxylamine). But even this amount of reduction is not to be ascribed to hydroxylamine in the solution, as it is due to the presence of mercurous sulphate. A drop of hydrochloric acid produced a white precipitate in the solution and

1 Formed by action of the air on dissolved nitric oxide. 
the filtrate from this was colored by the first drop of a very dilute potassium permanganate solution.

"Therefore hydroxylamine is not formed in measurable amounts during the chemical action of mercury on nitric acid under conditions approximating as closely as possible to those of my electrolytic experiments. That nitric oxide is formed has long been known. The same product is thus formed in both cases during the chemical reduction of nitric acid by copper and by mercury."

Experiments on the chemical action of lead on a mixture of nitric and sulphuric acids resulted chiefly in the formation of nitrous acid, the chemical action thus being different from that of either copper or mercury. In the electrolytic experiments a lead cathode gave more hydroxylamine than a copper one and less than a mercury one.

I have quoted from this paper of Tafel's at great length because we have here a series of carefully planned experiments which apparently prove conclusively that the electrolytic reduction is quite distinct in nature from the chemical reduction. As a matter of fact, this conclusion has been proved to be wrong as regards copper and is therefore probably wrong as regards mercury though this will have to be settled definitely by special experiments.

The matter of the copper in nitric acid has been cleared up by Turrentine ${ }^{1}$ in my laboratory. When copper reacts chemically with nitric acid, the anode product, copper nitrate is formed at the same spot that the reduction takes place. In the electrolytic reduction of nitric acid with a copper cathode, the reduction takes place in a solution practically free from copper salt. The conditions are therefore not the same in the two cases. This is the point that was overlooked by Tafel and which vitiates all his conclusions in regard to copper and presumably all those in regard to mercury and lead. To show that this difference in conditions was the cause of the difference in the products, Turrentine electrolyzed

${ }^{1}$ Jour. Phys. Chem., I0, 715 (1906). 
a solution of copper nitrate and nitric acid using a copper cathode. A gas was evolved at the cathode which proved on analysis to be chiefly nitric oxide. This experiment can be done in another way which is more striking. If dilute nitric acid be electrolyzed between copper electrodes, there will at first be no evolution of gas at the cathode. Gas will begin to appear as soon as the blue solution formed at the anode comes in contact with the cathode. A corollary to this is that ammonia would be formed in the chemical reaction between copper and nitric acid if the concentration of the copper salt could be kept sufficiently low. There did not seem to be any salt which one could add to the solution without introducing more complications than were eliminated, but Turrentine overcame the difficulty in another way. Strips of copper were hung vertically in a tall vessel. The copper nitrate flowed to the bottom of the vessel and the copper was removed by electrolytic precipitation in the form of cupric hydroxide. No current flowed through the copper strips and there was no copper cathode; but ammonia was formed.

These experiments of Turrentine's were performed to prove that the difference between the electrochemical and chemical corrosion of copper by nitric acid was an apparent one only and due to an unsuspected difference in the conditions. In addition, they illustrate the superior flexibility of the electrochemical method over the chemical method in conducting solutions. In the electrochemical method there is no difficulty in varying the concentration of the copper salt at the cathode between any desired limits, while this is very difficult to do in the case of the chemical method. This is in addition to the advantage, which the electrochemical method always has, of permitting a wide variation in the rate of reaction for constant temperature and constant concentration.

While the presence of ions of the cathode metal in solution is disadvantageous in the reduction of nitric acid to ammonia or hydroxylamine, this is not always the case. Indigotine is reduced to indigo white by zinc and alkali. 
Here the dissolving of the zinc is the anode reaction and the reduction of the indigotine at a zinc cathode is the cathode reaction. We should, therefore, expect to find that indigotine could be reduced at a zinc cathode in an alkaline solution in presence of zinc salts. This has been shown experimentally by Binz ${ }^{1}$ who found that little or no indigo white was obtained when there were no zinc salts in the cathode chamber. If the alkali had been concentrated enough to dissolve the zinc cathode readily, it would not have been necessary to have added zinc salts. This seems to be the case in the electrolytic reduction of nitrobenzene to aniline at a copper cathode in acid solution. $^{2}$ It was found that the reduction was equally successful whether one started with a copper cathode or with a platinum cathode and added copper salts to the solution. It is to be noticed that the direct action of copper on nitrobenzene produces aniline so that there is not the apparent discrepancy which was noted in the reduction of nitric acid.

The reduction of nitrates in neutral or alkaline solutions depends on the nature of the cathode. ${ }^{3}$ With gold, platinum, lead or iron cathodes, the chief reduction product is ammonia. With spongy copper or spongy silver cathodes the chief reduction product is nitrite and this is also the case with amalgamated copper cathodes. ${ }^{4}$ Müller and Weber ${ }^{5}$ have shown that the chemical action of copper on nitrate produces nitrite and not ammonia while Hatton ${ }^{6}$ has shown that spongy ion reduces nitrates chemically to ammonia. By measuring cathode potentials Müller and Spitzer ${ }^{7}$ have shown that the chemical behavior runs parallel with the depolarization values. The depolarization values are not always entirely

${ }^{1}$ Zeit. Elektrochemie, 5, 5, IO3 (1898).

2 Boehringer and Sons, D. R. P., I I6942, II 7007 (1899); Cf. Chilesotti: Zeit. Elektrochemie, 7, 768 (1901).

${ }^{3}$ Müller and Weber: Zeit. Elektrochemie, 9, 955 (1903); Müller and Spitzer: Ibid., Ir, 509 (1905).

${ }^{4}$ W. J. Müller: Ibid., 9, 978 (1903).

${ }^{5}$ Ibid., 9, 965 (1903).

' Jour. Chem. Soc., 39, 27 (188I).

${ }^{7}$ Zeit. Elektrochemie, II, 509 (1905). 
trustworthy. ${ }^{1}$ There may be catalytic actions due to the metals which may not show as a potential difference. ${ }^{2}$ The one thing which will always hold true is that the chemical action and the electrolytic action will be identical provided the conditions are the same in the two cases. Foerster ${ }^{3}$ has called attention to the parallelism between the chemical action and the cathode behavior of metals. Among other instances he cites the behavior of chloric acid which is readily decomposed by iron ${ }^{*}$ and is also readily reduced electrolytically at an iron cathode. ${ }^{5}$

As regards the electrolytic reduction of nitric compounds I quote the remarks of Buchner ${ }^{8}$ at the tenth annual meeting of the German Bunsen Society in Berlin.

"In my work on the electrolytic reduction of aromatic nitro compounds to the corresponding amines I started with the idea that when a metal reduced a nitro compound chemically and quantitatively to the corresponding amine, that metal must produce the same results under electrolytic conditions either as cathode or when added to the cathode because it would be carried into solution chemically and would be precipitated electrolytically by the current. As a matter of fact I was able to show experimentally that a whole series of metals kept their specific chemical action during electrolysis. Thus in acid solution one can reduce aromatic nitro compounds to the corresponding amines with iron, tin, lead and copper, either chemically or electrolytically. Similarly one can reduce aromatic nitro compounds in alkaline solution to hydrazo compounds chemically with tin, zinc, and lead while according to the Bayer patents the same reduction products can be obtained electrolytically with electrodes of these metals.

${ }^{1}$ Müller: Zeit. anorg. Chem., 26, I (Igor); Riss: Zeit. phys. Chern., 44, 64I (1904).

${ }_{2}^{2}$ Tafel: Zeit. Elektrochemie, 9, 645 (Igo3).

${ }^{3}$ Elektrochemie wässeriger Lösungen, 308 .

"Hendrickson: Am. Chem. Jour., 32, 242 (1904)

${ }^{5}$ Foerster: Zeit. Elektrochemie, 4, 386 (1898).

${ }^{B}$ Ibid., 9, 646 (r903) 
"From my point of view excess voltages and catalytic actions are of much less importance in these cases than the specific chemical effects. The matter is entirely different, however, in my experiments on the electrolytic reduction of aromatic nitro compounds to the corresponding amines in alkaline solution with a copper cathode. Here it is not possible to speak of a purely chemical action and I rather favor the view that we are dealing with a catalytic action of copper. Copper can scarcely be detected chemically in the solution while in the other cases of the acid solution salts of the cathode metal were always present in the electrolyte. Thus in the reduction of nitrobenzene in hydrochloric acid solution with a copper cathode, a double salt with the amine is present in the solution if the current is not allowed to run too long."

Personally I should not make the distinction into two classes as Buchner does. There are enough experiments with metals in strongly acid or strongly alkaline solutions to show that the reduction of nitrobenzene to aniline at a copper cathode is what would take place as the cathode reaction if copper were to dissolve in caustic soda with an evolution of hydrogen. The chemical method, as I have said before, is less flexible than the electrochemical method in conducting solutions; but that does not involve any new principle. If one is to distinguish two classes at all, they must correspond to the reduction of nitric acid at a copper cathode in the presence or absence of a copper salt. While we do not know to what the so-called "excess voltage" is due, its effect appears in the same way both in the chemical and the electrolytic experiments.

The instances of the identity between chemical and electrolytic reactions have been taken so far from the cathode reactions. We can find a number of interesting cases among the anode reactions, illustrating the same point. The oxidation of chromic sulphate to chromic acid takes place more readily at lead peroxide anodes than at those of platinum ${ }^{1}$

${ }^{1}$ Regelsberger: Zeit. Elektrochemie, 6, 308 (1899. Le Blanc: Ibid., 7, 292 (I900). Müller and Soller: Ibid., 863 (I905) 
and lead peroxide oxidizes chromic sulphate to chromic acid. The electrolytic formation of periodate at a lead peroxide anode is merely an electrolytic duplication of the chemical reaction. ${ }^{1}$ Kempf $^{2}$ states that in dilute sulphuric acid solution lead peroxide oxidizes benzene to quinone and that this reaction can be carried out electrolytically by using lead anodes. Sebor ${ }^{3}$ finds that $p$-toluene sulphonic acid is scarcely oxidized at all at a platinum anode while it is readily oxidized at a lead cathode. No explanation for this phenomenon was offered by him, but there seems no reason to suppose that this case is different in any way from the preceding three. The oxidation of ammonia to nitrites takes place in alkaline solutions in presence of oxygen and copper or cupric hydroxide. This has been duplicated electrolytically by Tafel and Biltz. ${ }^{4}$

Lö $b^{5}$ has shown that dimethylaniline can be oxidized at platinum anodes to tetramethyl benzidine provided chromic acid is added to the solution and that this is merely an electrolytic duplication of the chemical oxidation. The firm of Boehringer and Sons ${ }^{6}$ has made use of manganese salts as catalytic agents in electrolytic oxidation and has shown that these salts act chemically after having been converted electrolytically into manganic salts or permanganates as the case may be. White ${ }^{7}$ has extended the work of Lorenz ${ }^{8}$ on ferromanganese anodes and has shown that the electrolytic and chemical phenomena run parallel throughout. Walker ${ }^{8}$ has shown that the rusting of iron is essentially an electrolytic phenomenon and Curry ${ }^{10}$ has shown that the chemical and the electrolytic corrosions are the same in the case of the bronzes.

1 Müller: Zeit Elektrochemie,, ro, 49 (1904).

${ }^{2}$ Ibid., 7, 592 (I9OI).

${ }^{8}$ Ibid., 9, 370 (1903).

${ }^{4}$ Ber. chem. Ges. Berlin, 37, 3r 30 (1904). Cf. Müller and Spitzer: Ibid., 38, 779 (1905).

${ }^{5}$ Löb: Zeit. Elektrochemie, 7, 603 (1901).

${ }^{B}$ Ibid., 7, 625 (I9OI); 8, 219 (I9O2).

7 Jour. Phys. Chem., I0, 502 (1906).

${ }^{8}$ Zeit. anorg. Chem., 12, 393 (1896).

9 Jour. Am. Chem. Soc., 29, 1251 (1907).

${ }_{10}$ Jour. Phys. Chem., 10, 474 (1906). 
The behavior of cobalt salts in preventing the formation of hypochlorites ${ }^{1}$ is known to be due to the chemical action of the cobalt salt on the hypochlorite, oxygen being set free and the cobalt salt oxidized to cobaltic hydroxide. At ordinary temperatures the effect ceases as soon as all the cobaltous salt has been oxidized to cobaltic salt. It has been said that this becomes a true case of catalysis at higher temperatures; but this point calls for further study.

The data at hand do not seem to warrant any definite conclusion as to the cause of the catalytic action of chlorides, chlorates, sulphates and fluorides on the formation of periodates ${ }^{2}$ or of chlorides ${ }^{3}$ or fluorides on the formation of persulphates. ${ }^{4}$ We get an "excess voltage" at the anode corresponding in some respects to that at the cathode. The analogy is probably closer than it seems at first sight because a cadmium salt in solution raises the voltage at which hydrogen precipitates at a platinum cathode. When we can explain either set of phenomena, we shall probably be able to explain the other. With the fluoride it seems quite certain that there is some relation between the greater oxidizing effect in fluoride solutions and the formation of ozone when fluorine acts on water.

While we are somewhat at a loss in this case, it is a pleasure to note that Foerster ${ }^{b}$ calls attention to the fact that the somewhat complicated reaction in the electrolytic formation of perchlorate from chlorate is precisely the same as the chemical reaction.

In a previous paper ${ }^{7}$ I have pointed out that the electrolytic deposition of metals from solutions follows the general

${ }^{1}$ Oettel: Zeit. Elektrochemie, 5, 3 (1898).

${ }^{2}$ Müller: Ibid., Io, 64, 753 (I904). Cf. Skirrow: Zeit. anorg. Chem., 33, 25. Levi: Zeit. Elektrochemie, I2, 433 (1906).

${ }^{3}$ Elbs and Schönherr: Zeit. Elektrochemie, 2, 250 (1895).

${ }^{4}$ Müller: Ibid., ro, 776 (1904); 13, 681 (1907).

${ }^{5}$ It is quite possible that the effect of manganese salts on electrolytic oxidation may be due to the same cause.

' Elektrochemie wässeriger Lösungen, 49o. Cf. Oechsli: Zeit. Elektrochemie, 9,807 (1903).

' Jour. Phys. Chem., 9, 277 (1905); 12, 36 (1908). 
laws of chemical crystallization and that the conditions favoring the production of large crystals by chemical methods are also those which give rise to a relatively coarse crystallization when a metal is precipitated electrolytically.

When we come to cases of apparently abnormal electrolysis, a knowledge of the chemical reactions involved helps us out. These reactions were first studied by Luther. ${ }^{1}$ With an alkaline methyl alcohol solution containing a gold salt he obtained gold at the anode. What happens is that the alcohol is oxidized to aldehyde which then reduces the gold salt. With concentrated sodium carbonate and either permanganate or gold, we have a reduction to manganate or to metallic gold as the case may be. Here the intermediate stages are percarbonate and hydrogen peroxide, this last being the actual reducing agent. With sulphuric acid and permanganate there is also a reduction at the anode, due to the formation of persulphuric acid and of hydrogen peroxide. With a slightly acid nitrate solution to which potassium iodide has been added, iodine is obtained at the cathode. The current reduces nitric acid to nitrous acid and this last oxidizes the iodide to iodine. Kaufmann ${ }^{2}$ has shown that an iron cathode dissolves in ammonium nitrate solution. This is because the current forms an ammoniacal ammonium nitrate solution which in itself dissolves iron. A much more remarkable case is that discovered by Kraus $^{3}$ that lead dissolves at the cathode and precipitates at the anode during the electrolysis of a solution of $\mathrm{NaPb}_{2}$ in liquid ammonia between lead electrodes. This seems to be due to the existence of $\mathrm{Pb}_{2}^{\prime}$ as an univalent anion in liquid ammonia. Tafel ${ }^{4}$ reports the dissolving of mercury cathodes when methyl ethyl ketone is electrolyzed in acid solution. Beet $z^{5}$ has observed the evolution of hydrogen at a magnesium

1 Zeit. Elektrochemie, 8, 647 (rgor).

2 Ibid., 7, 733 (rgor).

${ }^{3}$ Jour. Am. Chem. Soc., 29, 1563 (1907).

4 Ber. chem. Ges. Berlin, 39, 3626 (I906).

${ }^{5}$ Phil. Mag. [4] 32, 269 (1866). 
anode, but this needs confirmation because it may be merely a case of disintegration of the anode. V. Meyer ${ }^{1}$ found that hydrogen acts on acidified permanganate solutions with evolution of oxygen. It follows from this that oxygen must be evolved at the cathode if one reduces acidified permanganate electrolytically. This prediction has been verified experimentally in my laboratory by Mr. Turrentine. Work is now being done to determine the nature of the reaction involved. Tommasi ${ }^{2}$ reports that both hydrogen and chlorine are set free at the cathode when chloral hydrate is reduced electrolytically. The reaction has not been studied further, so that it is impossible to say just what happens. There is no reason to suppose however that the explanation will be hard to find.

What seems to be a different type of case has just been discovered by Wood and Jones. ${ }^{3}$ On electrolyzing a double carbonate of copper and potassium, metallic copper was precipitated at both electrodes. So far as one can judge from the meagre details this seems to be a case of a complex anion breaking down and precipitating copper. This in itself does not seem very probable and one cannot help wondering whether the anode precipitate might not have been cuprous oxide as we know that it is in the electrolysis of Fehling's solution." The possibility of an intermediate formation of percarbonate should also be considered. That would make this case like Luther's experiment with sodium carbonate and a gold salt.

\section{ELECTROLYSIS IN NON-CONDUCTING SOLUTIONS}

While there is nothing about reactions in conducting solutions which is inconsistent with Faraday's conception of the equivalence and possible identity of chemical affinity and electrolysis, the case is very different when we come to reactions in organic solvents. The theory of Berzelius shat-

\footnotetext{
${ }^{1}$ Ber. chem. Ges. Berlin, 29, 2549, 2828 (Ig06).

${ }^{2}$ Elektrochemie, 74r.

${ }^{3}$ Proc. Camb. Phil. Soc., r4, 17 (1907).

4 Luther: Zeit. Elektrochemie, 8, 649 (IgO2).
} 
tered against the facts of organic chemistry and these same facts have checked the development of the theory of Faraday and Helmholtz. It is therefore only by a study of the facts of organic chemistry that we can settle to what extent the theory of Faraday is a good working hypothesis. In the remainder of this too long paper, I intend to point out how the problem is to be attacked. Some preliminary experiments are already under way in my laboratory and I hope that others will be interested enough in the problem to attack it themselves.

Under direct electrical methods we have the high frequency discharge, the silent discharge, and direct electrolysis. The silent discharge may be simply a light phenomenon, as we know it to be in the formation of ozone. If so, it should not be classified under the electrical methods. The method has not given the results which it should. This has been due in part to the essentially qualitative nature of the researches thus far carried out and in part to the fact that alternating current has been used instead of direct current. ${ }^{1}$ The high frequency discharge has yielded some very interesting results $^{2}$ and it is to be hoped that Messrs. Jackson and Laurie will continue these very promising investigations. Direct electrolysis is possible in some few cases; but its application is extremely limited practically. Of course we can claim that it is only the lack of time at our disposal which hinders u's. In one of the passages previously quoted, Helmholtz has stated this clearly." "In order to produce a current of sufficient strength to collect enough of the products of decomposition without producing too much heat in the electrolyte, the substance which we try to decompose ought not to offer too much resistance to the current. But this resistance may be great, and the motion of the ions may be very slow, so slow indeed that we should need to allow it to go on for hundreds of years before we should be able to collect

${ }^{1}$ Trans. Am. Electrochem. Soc., 9, 20 (1906).

${ }^{2}$ Jackson and Laurie: Proc. Chem. Soc., 22, I 55 (1906).

${ }^{3}$ Helmholtz: Jour, Chem, Soc., 39, 29I (I88I). 
even traces of the products of decomposition; nevertheless all the essential attributes of the process of electrolysis could subsist." Such an argument is entirely satisfactory for the use which Helmholtz makes of it, namely, to show that the theory of Faraday is not necessarily inconsistent with the phenomena of organic chemistry. On the other hand it is of no account as a means of proving that Faraday's theory does represent the facts. To test this latter question we must devise what I have called rapid methods of electrolysis in non-conducting solutions.

The line of argument is similar to that in which it was shown that chemical affinity could be calculated from the van't Hoff formula. Chemical affinity as calculated from the equilibrium relations was found to be equal to that calculated from electromotive force measurements in all cases where the two were comparable. We therefore conclude that the equilibrium relations enable us to calculate what would be the electromotive force which a cell would have if it could be so constructed as to give us the ester formation, for instance. If we can now show that certain non-electrical methods give the same results as electrolysis in all cases in which a comparison is possible, we are justified in concluding that these same non-electrical methods will give results in other cases which are identical with those which we should get if the solution conducted sufficiently well to make electrolysis practicable.

First among these methods comes the Gladstone and Tribe zinc-copper couple. ${ }^{1}$ The couple reduces a potassium nitrate solution first chiefly to nitrite and then to ammonia if experiments are made at ordinary temperature. ${ }^{2}$ This is exactly what was found by Müller and Spitzer $^{3}$ for electrolytic reduction with a copper cathode. 'Working in hot solutions Thorpe ${ }^{4}$ was able to develop a quantitative method

1 Proc. Roy. Soc., 20, 218; Jour. Chem. Soc., 25, 461 (1872).

2 Gladstone and Tribe: Jour. Chem. Soc., 33, 140 ( 1878 ).

${ }^{3}$ Zeit. Elektrochemie, II, 509 (I905).

${ }^{4}$ Jour. Chem. Soc., 26, 54I (1873). 
for determining nitrites as ammonia. The object of heating the solutions was to accelerate the reaction; and we know that at silver cathodes raising the temperature is unfavorable to the nitrite formation ${ }^{1}$ but it is not fair to assume that the effect would be more marked in the case of copper cathodes under similar conditions. ${ }^{2}$ It is interesting to note Thorpe's experience with ammonium nitrate. ${ }^{3}$

"Of all the nitrates experimented upon, the most difficult of reduction appears to be ammonium nitrate. From the irregularity of the results obtained, I was inclined to believe that the decomposition was incomplete, or that hydroxylamine might be formed, or possibly Divers' hyponitrous acid. Direct experiments, however, have failed to point out the formation of these substances. The discordances appear to depend upon differences in the strength of the solution and the amounts of zinc and copper taken. If the solution is too strong, nitrogen dioxide is evolved, and if the amount of zinc and copper be insufficient the reduction is incomplete."

In view of what we know as to the solvent action of an ammonium nitrate solution on copper, it is probable that the case is similar to that of reduction in an acid solution in presence of a copper salt. This is confirmed by the experiments of Gladstone and Tribe."

The zinc-copper couple reduces a hot solution of potassium chlorate to chloride ${ }^{5}$ and the same result was obtained

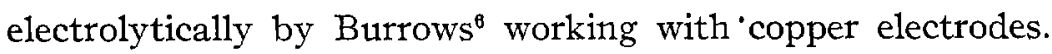
The couple reduces nitrobenzene to aniline ${ }^{7}$ and we have already seen that this same reduction takes place electrolytically at a copper cathode. ${ }^{8}$ The couple reduces indigo-blue

${ }^{1}$ Müller and Spitzer: Zeit. Elektrochemie, II, 513 (1905).

${ }^{2}$ Cf. C. F. Boehringer and Söhne: Zeit Elektrochemie, 12, 745 (1906)

${ }^{8}$ Jour. Chem. Soc., 26, 544 (1873).

4 Ibid., 33, I5I (1878).

B Thorpe: Ibid., 26, 547 (I873). Ėccles: Ibid., 29, 856 (1876). Gladstone and Tribe: Ibid., 33, 447 (1878).

' Jour. Phys. Chem., 6, 417 (1902); 7, 537 (1903).

7 Gladstone and Tribe: Jour. Chem. Soc., 33,312 (1878).

${ }^{3}$ Chilesotti: Zeit. Elektrochemie, 7, 768 (Igor). 
to indigo-white in an alkaline solution, and Binz $z^{1}$ has shown that the same reduction takes place electrolytically at a zinc cathode with a zinc salt in solution. Unquestionably the same result could be obtained with a zinc salt in solution and a copper cathode. The couple reduces arsenious acid to arseniuretted hydrogen. The same reaction takes place in the Marsh test with zinc in an acid solution, in other words at a zinc cathode. I do not know of any experiments with a copper cathode but I think there can be no question as to what the result would be.

These cases illustrate the identity between the action of the couple and that of the electrolytic cell. We now come to some intermediate cases. At $50^{\circ}$ the couple reacts with chloroform dissolved in absolute alcohol, forming chiefly methane and zinc chloro-ethylate. ${ }^{2}$ Small amounts of acetylene are also formed, the ratio of acetylene to methane increasing as we change from chloroform to bromoform and then to iodoform. Zinc foil alone does not react so rapidly or at so low a temperature as the couple but the final products are the same except so far as some acetylene may be retained by the copper. A solution of chloroform in absolute alcohol practically does not conduct at all; but some experiments made in my laboratory some years ago showed that chloroform could be decomposed electrolytically in alcoholic solution between zinc electrodes. Under these conditions it is not worth while to attempt much in the way of quantitative electrolysis. Fortunately, Gladstone and Tribe have tried some experiments with alcohol containing up to 25 percent of water. Oxychloride of zinc is formed instead of zinc chloroethylate; but that seems to be the chief difference. The gaseous product is almost entirely methane as before. $\mathrm{Fx}-$ periments are now being made in my laboratory on the electrolysis of these solutions. While the work is not yet finished, it has been established that chloroform is decomposed and

${ }^{1}$ Zeit. Elektrochemie, 5, 5, 103 (1898).

${ }^{2}$ Gladstone and Tribe: Proc. Roy. Soc, 20, 218 (1872); Jour. Chem. Soc., 33, 508 (I875); 
that methane is formed. The quantitative details will be given later.

Since the chief gaseous product is methane whether we work with chloroform in absolute alcohol or in aqueous alcohol, and since the electrolysis of the solutions in aqueous alcohol gives results paralleling those with the couple in the same solutions, we are justified in concluding that electrolysis in the absolute alcohol solution, would merely duplicate the results obtained by Gladstone and Tribe. There is however no obvious reason why we should differentiate between the decomposition of chloroform, bromoform or iodoform by the couple on the one hand and the decomposition of methyl or ethyl iodide ${ }^{1}$ on the other hand. No solvent was used and the couple was added direct to the methyl iodide. The reaction is slow at ordinary temperatures and the first product is zinc methiodide which breaks down readily into zinc methyl and zinc iodide. The system does not conduct to any appreciable extent so far as we know; but we are undoubtedly getting the products which we should get if we could electroblyze methyl iodide between zinc electrodes. The following passage shows what Gladstone and Tribe ${ }^{2}$ themselves thought about their couple.

"We have not hesitated in our papers to call the agent which we employ 'the copper-zinc couple,' although aware that this has frequently led to misapprehension. The term suggests to many minds the metallic elements of a voltaic battery, and the first impression conveyed has frequently been that we were using a battery of low intensity with its conducting wires, etc. We have, however, purposely retained the term because we have all along believed that the action was really of the same character as that which takes place in ordinary electrolysis, and indeed was identical with what occurs within the voltaic cell. There are two metals in contact, standing in the decomposable liquid, only instead of one

${ }^{1}$ Gladstone and Tribe: Jour. Chem. Soc., 35, 10,556 (1879). Cf. I,achmann: Am. Chem. Jour. I9, 410 (1897).

${ }^{2}$ Jour. Chem. Soc., 35, 571 (1879). 
pair of plates, or several pairs joined together, we have minute pieces of metal, forming myriads of circuits. There is this great advantage also in our arrangement, that the resistance of the binary compound is reduced to a minimum as it washes the very points of contact of the metals:"

If we call the Gladstone and Tribe zinc-copper couple the first of our methods of performing electrolysis in nonconducting solutions, the second method should be called the chemical production of ions. ${ }^{1}$ When sodium persulphate or persulphuric acid breaks down in aqueous solution we get the setting free of the sulphate ions. We should therefore expect to get the characteristic reactions of the sulphate ion, and we actually get just that. In an aqueous solution of persulphuric acid, either by itself or in contact with platinum, oxygen is evolved, the reaction being inproved from a spectacular point of view by addition of a little manganous sulphate. When a strip of copper is placed in a sodium persulphate solution the amount of persulphate decomposed in any period of time is exactly equivalent ${ }^{2}$ to the amount of copper changed into copper sulphate. This is as it should be because copper dissolves practically quantitatively when made anode in a sulphate solution. On the other hand nickel and aluminum do not dissolve to any great extent when made anodes in sulphate solutions and they are therefore not corroded by a sodium persulphate solution. Of course it might be urged that this chemical reaction is not strictly parallel to the electrolytic action, because we have the preliminary breaking up of the persulphate ion, $\mathrm{S}_{2} \mathrm{O}_{8}{ }^{\prime \prime}$, which might introduce unknown complications. While $I$ do not admit the validity of this hypothetical objection, there is another way in which we can duplicate chemically the action of electrolysis of sulphate solutions. Cobaltic sulphate breaks down spontaneously on gentle heating and sets free sulphate as ion. Ordinarily this is accomplished by the setting free of oxygen and the formation of sulphuric acid just as in the case

${ }^{2}$ Cf. Trans. Am. Electrochem. Soc., 8, 43 (1905).

2 Turrentine: Jour.. Phys. Chem., Ir, 623 (1907). 
of electrolysis. Since the relatively stable ferric sulphate reacts with copper there can be no doubt that the instable cobaltic sulphate would do the same. Now if we were to allow some organic liquid to react with dry sodium persulphate which we can get or with anhydrous cobaltic sulphate which probably we cannot get, we could certainly speak of electrolysis in a non-conducting solution if our reaction product were to be a sulphonic acid for instance. I am not familiar with any experiments along this line with sulphates; but we get a parallel case with lead tetrachloride and Polis ${ }^{1}$ states that chlorbenzene is formed when lead tetrachloride reacts with benzene. The weak point in this is that Polis did not start with lead tetrachloride and benzene. He started with lead tetraphenyl and hydrochloric acid, postulating the intermediate formation of the other pair of compounds.

Some experiments that we have made point to the fact that Polis was probably right in his conclusions though his method of reaching them may not have been orthodox. This is not an isolated case. In cobaltic sulphate we had a salt which broke down of its own accord because the metal radical changed valency. In ferric sulphate we have a substance which does not break down spontaneously into ferrous salt; but the valency of the metal radical can vary and we get the same reaction between copper and ferrous sulphate as between copper and cobaltic sulphate. In lead tetrachloride we have a basic radical with a varying valence and a compound which breaks down very easily. With benzene, lead tetrachloride acts as a halogen carrier substituting chlorine in the ring. The halogen carriers in actual use contain a basic radical with a varying valence. Though they are comparatively stable by themselves, they react with benzene substituting chlorine in the ring. The analogy is a bit striking and brings us very close to a working theory of halogen carriers. I shall not develop this further now because it belongs properly in a later paper on the electrochemistry of light.

\footnotetext{
${ }^{1}$ Ber, chem. Ges. Berlin., 20, 7 16 (I887).
} 
The percarbonates stand in the same relation to carbonates as the persulphates to sulphates. Addition of potassium cyanide or potassium iodide to copper sulphate solution sets free cyanogen or iodine respectively. These methods have found no application so far in organic chemistry. On the other hand Mulliken ${ }^{1}$ has shown that the same new ester is formed whether we electrolyze sodium malonic ester or whether we add iodine to the solution.

The many reductions with zinc dust, with aluminum amalgam or with sodium amalgam, are all essentially cases of electrolysis in a non-conducting, solution. They are to be classified as cases intermediate between the zinc-copper couple and the chemical production of ions.

As still a third method we have the action of light. If we adopt the theory of Grotthuss, ${ }^{2}$ and look upon a ray of light as equivalent to a voltaic cell, the chemical actions of light become really electrochemical actions and we have found another very useful method of doing electrolysis in nonconducting solutions. Work is now being carried on in my laboratory to prove the correctness and usefulness of this. theory of Grotthuss, so I will only call attention to the large number of reactions which will be included under this head if we succeed in establishing the validity and applicability of the theory of Grotthuss.

\section{SUMMARY}

A necessary prerequisite to the general application of sume modification of the theories of Berzelius and of Faraday is the proof of the existence of a polar state in organic compounds. The issue is clearly joined between Nernst $^{3}$ who believes in a non-polar union and Abegg ${ }^{4}$ who upholds the polar view. Incidentally, any one upholding a polar theory must put forward some fairly definite hypothesis as to the

\footnotetext{
${ }^{1}$ Am. Chem. Jour., 15, 523 (1893).

2 Ostwald's Klassiker, r52, I 5 .

${ }^{3}$ Zeit. Elektrochemie, 7, 1005 (I901).

4 Zeit. anorg. Chem., 39, 374 (1904).
} 
conditions under which a definite element or a definite group can change from being positively polar to being negatively polar. In the reaction between zinc and methyl iodide for instance, the zinc is certainly positive in the compounds, zinc methiodide, zinc methyl and zinc iodide, while methyl and iodine are the negative radicals. In methyl iodide however the methyl group is presumably positive. Until we can tell something more definite about the conditions for the change of polarity, none of the conclusions drawn by Abegg are really binding. Take the case of iodine monochloride for instance. This reacts with caustic potash to form potassium chloride and hypoiodite. Abegg therefore considers iodine as positive and chlorine as negative. In HIO, however, the ions are $\mathrm{H}^{\cdot}$ and $\mathrm{IO}^{\prime}$ instead of $\mathrm{I}^{\cdot}$ and $\mathrm{OH}^{\prime}$. We know that there has been a re-arrangement here and it seems difficult to prove that no other re-arrangements have taken place. It is conceivable that potassium iodide and hypochlorous acid were an intermediate step. In that case our conclusions would be reversed. As another instance, take the reaction between chlorine and benzene. It is certainly simpler to say that the positive chlorine replaces the positive hydrogen and that the negative chlorine unites with the positive hydrogen to form hydrochloric acid. In chlorbenzene, however, it would be natural to consider chlorine as negative and the phenyl radical as positive. In that case we should say that the negative chlorine replaced the negative hydrogen and that the positive chlorine combined with the negative hydrogen to form hydrochloric acid, in which there was afterwards a rearrangement such that the hydrogen becomes positive and the chlorine negative. This does not seem so attractive a way of putting it as the first one; but there is no way at present of proving that it is wrong. When hydrogen is set free electrolytically, we must assume a rearrangement if we are to consider hydrogen gas as polar. Another difficulty occurs in the case of monatomic sodium vapor. We cannot postulate a molecular compound as in the case of hydrogen or chlorine. A 
solution is possibly to be found in Nernst's theory of the chemical nature of electricity. ${ }^{1}$

All these difficulties are swept away at one stroke by Nernst's assumption of non-polar compounds. This would be a great relief if it were not that we introduce new complications. According to Nernst hydrochloric acid is a polar compound and ethyl chloride is not; but if we keep away from conducting solutions there seems to be no just reason for differentiating between hydrochloric acid and ethyl chloride. The existence of a definite polar compound ${ }^{2} \mathrm{NaPb}_{2}$ is also a serious matter from the Nernst point of view. More serious still, is the fact that Nernst's view practically excludes all the possibilities to which I have called attention under the heading of electrolysis in non-conducting solutions. If the action of the Gladstone and Tribe couple on chloroform or methyl iodide is truly an electrolysis, it is difficult to see how there can be anything more than a qualitative difference between organic and inorganic compounds. Nernst's treatment of organic reducing agents and oxidizing agents $^{3}$ in terms of the hydrogen and oxygen electrodes respectively is inconsistent with his other position, and we are forced to conclude that the conception of organic substances as polar compounds is likely to prove fruitful experimentally.

If we grant the existence of polarity for the sake of argument, we come next to the extent of the subdivision. With potassium chloride we recognize only two ions, potassium and chlorine; but how about potassium nitrate? We can reduce it at the cathode to nitrite and it is therefore an oxidizing agent capable of setting up a definite oxygen concentration at a platinum electrode. Nernst's point of view in regard to oxidizing agents has proved a useful one and if

${ }^{1}$ Nernst: Zeit. Elektrochemie, 7, 1005 (I901).

${ }^{2}$ It is interesting to note that lead tetraphenyl is made by the action of $\mathrm{NaPb}_{2}$ on chlorbenzene, by the substitution of negative lead for negative chlorine. One is tempted to predict that tin will be anion when sodium and tin are disolved in liquid ammonia.

${ }^{3}$ Nernst and Lessing: Cf. Foerster, Elektrochemie wässeriger Lösungen, I27. 
we adopt it, we must postulate some such reversible dissociation as that given by the equation

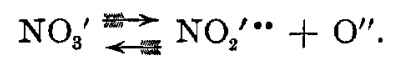

This is merely the Berzelius theory over again and the only question is where we are to stop. There is still reduction to nitric oxide to be accounted for. It is not merely a question of organic chemistry. The electrolytic reduction of the nitrates, the nitrites, the chlorates, the sulphates, ${ }^{1}$ etc., brings us face to face with the dilemma. Either we must apply some form of the Berzelius theory to these cases or we must revise all our present theoretical views in regard to electrolytic reduction and oxidation. There can be very little doubt as to what the answer will be to this. Since there is no experimental justification for distinguishing fundamentally between the reduction of nitrates and nitrobenzene, we come back again to the probable application of the Berzelius theory in some form to organic compounds.

The general results of this paper may be summed up as follows :

(I) Electrolytic and chemical actions are identical when carried on under the same conditions.

(2) The so-called "excess voltage" phenomena at metallic cathodes are duplicated when these metals are attacked chemically.

(3) Electrolysis in non-conducting solutions can be carried on with the zinc-copper couple; with sodium amalgam, aluminum amalgam, zinc dust, etc.; by chemical production of ions; and by means of light.

(4) Nernst's theory of non-polar compounds in the case of hydrogen, chlorine and the carbon compounds is inconsistent with his theory of oxidizing and reducing agents.

(5) The evidence is in favor of the general applicability of some modification of the dualistic theory of Berzelius.

(6) The evidence is in favor of the general applicability

${ }^{1}$ Abegg: Zeit. anorg. Chem., 39, 374 (1904). 
of some modification of Faraday's theory in regard to chemical affinity and electricity.

(7) We are handicapped by the lack of a definite theory as to the conditions under which a change of polarity takes place.

(8) It is possible that Nernst's theory of the chemical nature of electricity may be developed so as to help out on the question of reversible polarity.

Cornell University. 